\title{
Modelling Bending Wave Transmission across Coupled Plate Systems Comprising Periodic Ribbed Plates in the Low-, Mid-, and High-Frequency Ranges Using Forms of Statistical Energy Analysis
}

\author{
Jianfei Yin ${ }^{1}$ and Carl Hopkins ${ }^{2}$ \\ ${ }^{1}$ Vibration and Acoustics Research Group, Laboratory of Science and Technology on Integrated Logistics Support \\ National University of Defense Technology, Changsha, Hunan 410073, China \\ ${ }^{2}$ Acoustics Research Unit, School of Architecture, University of Liverpool, Liverpool L69 7ZN, UK \\ Correspondence should be addressed to Carl Hopkins; carl.hopkins@liv.ac.uk
}

Received 14 May 2015; Revised 11 July 2015; Accepted 3 August 2015

Academic Editor: Marco Alfano

Copyright (C) 2015 J. Yin and C. Hopkins. This is an open access article distributed under the Creative Commons Attribution License, which permits unrestricted use, distribution, and reproduction in any medium, provided the original work is properly cited.

Prediction of bending wave transmission across systems of coupled plates which incorporate periodic ribbed plates is considered using Statistical Energy Analysis (SEA) in the low- and mid-frequency ranges and Advanced SEA (ASEA) in the high-frequency range. This paper investigates the crossover from prediction with SEA to ASEA through comparison with Finite Element Methods. Results from L-junctions confirm that this crossover occurs near the frequency band containing the fundamental bending mode of the individual bays on the ribbed plate when ribs are parallel to the junction line. Below this frequency band, SEA models treating each periodic ribbed plate as a single subsystem were shown to be appropriate. Above this frequency band, large reductions occur in the vibration level when propagation takes place across successive bays on ribbed plates when the ribs are parallel to the junction. This is due to spatial filtering; hence it is necessary to use ASEA which can incorporate indirect coupling associated with this transmission mechanism. A system of three coupled plates was also modelled which introduced flanking transmission. The results show that a wide frequency range can be covered by using both SEA and ASEA for systems of coupled plates where some or all of the plates are periodic ribbed plates.

\section{Introduction}

Periodic ribbed plates with symmetric ribs are found in engineering structures such as ships, aircraft, spacecraft, and buildings [1]. At the design stage it is essential to consider noise control in order to reduce reradiated sound from mechanical excitation, as well as structure-borne sound transmission to vulnerable parts of a structure that support sensitive equipment. This requires the availability of validated prediction models in the audio frequency range that can consider both structure-borne sound transmission and sound radiation.
For isolated periodic ribbed plates, there is a large literature concerning the prediction of vibration fields (e.g., see [2-4]). However, the problem of predicting vibration transmission between coupled periodic ribbed plates is not fully addressed; hence this is considered in this paper. For built-up structures that comprise at least two coupled plates it is common engineering practice to use Finite Element Methods (FEM) for structural dynamics in the low- and midfrequency range. However, this can be computationally intensive when including fluid-structure interaction to predict the sound radiated into acoustic cavities. An alternative approach to modelling in the audio frequency range is Statistical 
Energy Analysis (SEA). This provides a computationally efficient basis on which sound and vibration transmission and sound radiation are predicted in large built-up structures that are formed from relatively simple isotropic and homogeneous beams and plates for both steady-state [5] and transient $[6,7]$ sources of mechanical vibration. The application of SEA to periodic ribbed plates has previously been described as potentially problematic due to the existence of spatial filtering and indirect coupling [8]. However, Advanced SEA (ASEA) [9] can incorporate indirect coupling (sometimes referred to as tunnelling mechanisms) within a statistical framework of analysis in the high-frequency range. The present authors [10] have shown that ASEA allows accurate prediction of bending wave transmission across an Ljunction comprising a periodic ribbed plate with symmetric ribs and an isotropic homogeneous plate. In contrast, SEA significantly underestimated the vibration response in the bays of the ribbed plate when the isotropic homogeneous plate was excited. This occurs due to the absence of tunnelling mechanisms in SEA. ASEA is able to provide significantly more accurate predictions by accounting for the spatial filtering that leads to nondiffuse vibration fields on the more distant bays of the ribbed plate. Wilson and Hopkins [11] have subsequently shown that the application of ASEA can be extended to large built-up structures formed from many plates through the use of a beam tracing method to increase the computational efficiency. To complement this predictive capability for periodic ribbed plates using ASEA, the present authors [12] have recently validated SEA predictions in the low- and mid-frequency ranges for the same type of Ljunction but where one plate or both plates were a periodic ribbed plate. This showed that when the ribs were parallel to the junction, SEA models that incorporated a combination of Bloch theory and wave theory showed good agreement with measurements and FEM models. Note that Wave Intensity Analysis (WIA) is an alternative approach to ASEA that can also account for indirect coupling and spatial filtering [13].

For systems of coupled plates which incorporate periodic ribbed plates with symmetric ribs, this paper investigates the crossover from the SEA model for the low- and midfrequency ranges to the ASEA model for the high-frequency range. This crossover is expected to occur in the frequency range where the bays on the ribbed plate begin to support local bending modes. The aim is to provide evidence of how a wide frequency range can be covered by using both SEA and ASEA. This paper also shows new comparisons of SEA and FEM for the high-frequency range because previous work by the present authors [12] only focussed on the application of Bloch theory in the low- and mid-frequency ranges. The reason to do this is to investigate whether SEA incorporating Bloch theory gives a reasonable estimate of the spatial average vibration over all the bays on the ribbed plate in the highfrequency range. If so, this needs to be considered in the context of whether it is reasonable to treat a ribbed plate as a single subsystem when the response between the bays is significantly different. These findings are then applied to a system of three coupled plates in order to provide a more rigorous test of its application to more realistic structures where flanking transmission usually occurs.

\section{Materials and Methods}

This section describes the FEM, SEA, and ASEA models and the plate junctions which incorporate periodic ribbed plates with symmetric ribs.

2.1. Finite Element Models. COMSOL Multiphysics 5.0 software is used to carry out FEM calculations on an IBM x3650 M4 workstation cluster. FEM calculations were carried out in $5 \mathrm{~Hz}$ steps over the frequency range that encompassed onethird octave bands from $100 \mathrm{~Hz}$ to $10 \mathrm{kHz}$. Both the plates and ribs are modelled using a shell element for which the formulation is the Mindlin-Reissner type. This means that transverse shear deformations are accounted for, and it can be used for thick plates as well as thin plates although for the plates analysed in this paper the thin plate limit is above $10 \mathrm{kHz}$. Along the plate boundaries and the junction line connecting the two plates, the nodes are constrained in the three coordinate directions to ensure that, with excitation of bending waves on the source subsystem, no in-plane waves are generated at the junction of the two plates.

Rain-on-the-roof excitation is applied to all the unconstrained nodes on the source plate with forces of unity magnitude and random phase at different positions. This is achieved by defining a random function of the spatial coordinates in COMSOL with uniform distribution of the phase. Ten different sets of random phase values are used so that the ensemble output can be considered as representative of different physical realizations of rain-on-the-roof excitation.

2.2. SEA Model. The SEA matrix solution is given by [5]

$$
\begin{aligned}
& {\left[\begin{array}{ccccc}
\sum_{n=1}^{N} \eta_{1 n} & -\eta_{21} & -\eta_{31} & \cdots & -\eta_{N 1} \\
-\eta_{12} & \sum_{n=1}^{N} \eta_{2 n} & -\eta_{32} & & \\
-\eta_{13} & -\eta_{23} & \sum_{n=1}^{N} \eta_{3 n} & & \\
\vdots & & & \ddots & \\
-\eta_{1 N} & & & & \sum_{n=1}^{N} \eta_{N n}
\end{array}\right]\left[\begin{array}{c}
E_{1} \\
E_{2} \\
E_{3} \\
\vdots \\
E_{N}
\end{array}\right]} \\
& =\left[\begin{array}{c}
\frac{W_{\mathrm{in}(1)}}{\omega} \\
\frac{W_{\mathrm{in}(2)}}{\omega} \\
\frac{W_{\mathrm{in}(3)}}{\omega} \\
\vdots \\
\frac{W_{\mathrm{in}(N)}}{\omega}
\end{array}\right]
\end{aligned}
$$


where $W_{\text {in(i) }}$ is the power input into source subsystem $i, \omega$ is the band centre angular frequency, $\eta_{i i}$ is the internal loss factor of subsystem $i, \eta_{i j}$ is the coupling loss factor from subsystem $i$ to $j$ (when $i \neq j$ ), and $E_{i}$ is the time and space average energy of subsystem $i$.

To treat the periodic ribbed plate as a single subsystem, Tso and Hansen [14] combined Bloch theory and wave theory to determine the transmission coefficient across an L-junction formed by an isotropic, homogeneous plate and a periodic ribbed plate where each plate was treated as an individual subsystem. Yin and Hopkins [12] extended the theory to (a) allow calculation of the transmission coefficient in both directions without needing to estimate the modal density of the ribbed plate and (b) model an L-junction formed from two periodic ribbed plates. They also showed that when both plates are ribbed plates, one with ribs orientated perpendicular to the junction and the other with ribs parallel to the junction, SEA models which assume an effective isotropic plate or an equivalent isotropic plate or angle-dependent bending stiffness underestimate the energy level difference. However, the approach assuming angle-dependent bending stiffness from Bosmans et al. [15] was shown to give the best agreement. For this reason angle-dependent bending stiffness is used when calculating transmission coefficients to/from a ribbed plate when the ribs are perpendicular to the junction in this paper. The theory is described in detail in a previous paper by the present authors [12].

2.3. ASEA Model. ASEA was introduced by Heron [9] to account for indirect coupling by using ray tracing (ignoring phase effects) to track the power around coupled subsystems and then use SEA to deal with the residual power. Implementation of the calculation procedure is described in detail in [9-11]; hence only a brief summary is given here. For each angle of incidence, all power transfers are entered into a pair of coupling matrices, $\mathbf{A}$ and $\mathbf{B}$. Matrix $\mathbf{A}$ represents the power transfer from available power in a particular subsystem to available power in another subsystem (including that subsystem itself) whereas matrix $\mathbf{B}$ represents the transfer of available power to unavailable power. Assuming a diffuse field for each subsystem, this calculation is repeated for all possible angles of incidence. Diffuse field versions of matrices $\mathbf{A}$ and $\mathbf{B}$ are calculated by integrating over all angles of incidence. When the chosen level number of calculation has been reached, the residual power is removed from matrix A to maintain the power balance. The final step is to assign power input to corresponding subsystem(s) and solve the ASEA energy balance equations involving matrices $\mathbf{A}$ and $\mathbf{B}$ to calculate the subsystem responses. ASEA is defined by the solution of the following two equations:

$$
\begin{gathered}
\mathbf{P}=\mathrm{Ae}+\mathrm{Me}, \\
\mathbf{Q}=\mathrm{Be}+\mathrm{Md},
\end{gathered}
$$

where the available modal energy is denoted by $\mathbf{e}$, unavailable modal energy is denoted by $\mathbf{d}$, and $\mathbf{P}$ and $\mathbf{Q}$ are the available and unavailable power input, respectively. However for plates excited by rain-on-the-roof all the input power is available for transmission, so it can be treated as available power input in $\mathbf{P}$ whereas the unavailable power input in matrix $\mathbf{Q}$ is zero.

The subsystem response is given by $\mathbf{e}+\mathbf{d}$ once $\mathbf{A}, \mathbf{B}, \mathbf{P}$, and $\mathbf{Q}$ are known. The terms $\mathbf{M e}$ and $\mathbf{M d}$ give the available power lost and unavailable power lost within each subsystem. From (2) the sum of the modal energies is given by

$$
\mathbf{e}+\mathbf{d}=\mathbf{M}^{-1}(\mathbf{M}-\mathbf{B})(\mathbf{M}+\mathbf{A})^{-1} \mathbf{P} .
$$

ASEA calculations use an angular resolution of $0.01^{\circ}$ with a frequency resolution of $10 \mathrm{~Hz}$. The convergence criterion for the ASEA level is based on the energy level difference between the source subsystem and the most distant receiving subsystem changing by $<0.1 \mathrm{~dB}$ at all frequencies. To achieve this for the plate junctions in the present paper an ASEA level number equal to the number of subsystems is required.

2.4. Description of Plate Junctions. The L-junctions and the system of three coupled plates are shown in Figure 1. The parameters describing the ribbed plates are shown in Figure 2. All plates are assumed to be formed from Perspex for which the material properties and plate dimensions are given in Table 1.

The crossover from the SEA model to the ASEA model is expected to occur near the frequency corresponding to the fundamental bending mode of the bays. This frequency is estimated by assuming that the bay has simply supported boundaries. For the ribbed periodic plate that forms Plate 2 in L-junctions $\mathrm{A}$ and $\mathrm{B}$, the fundamental bending mode of the bays is estimated to occur in the $1 \mathrm{kHz}$ one-third octave band. For the ribbed periodic plate that forms Plate 1 in Ljunctions B and C and Plate 1 in the system of three coupled plates, it is estimated to occur in the $400 \mathrm{~Hz}$ one-third octave band.

\section{Results and Discussion}

In Section 3.1, the results from L-junctions $\mathrm{A}$ and $\mathrm{B}$ are discussed together because the ribs are parallel to the junction line; hence the effects of propagation over a periodic structure are expected to be evident. This is followed by a discussion of L-junction C in Section 3.2 for which the ribs are perpendicular to the junction line and there is not expected to be any particular advantage in using ASEA as spatial filtering will not occur. Section 3.3 then assesses the results from three coupled plates in the light of the findings on the L-junctions.

3.1. L-Junctions $A$ and $B$ (Ribs Parallel to the Junction). Figure 3 shows the propagation and attenuation zones for a bending wave with wave heading angles between $0^{\circ}$ and $90^{\circ}$ where $0^{\circ}$ is defined as being perpendicular to the junction line. Propagation zones correspond to purely imaginary propagation constants and attenuation zones correspond to a 


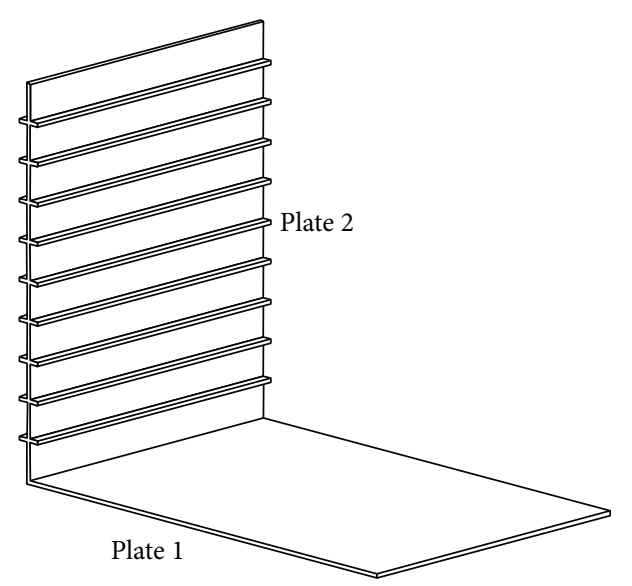

(a)

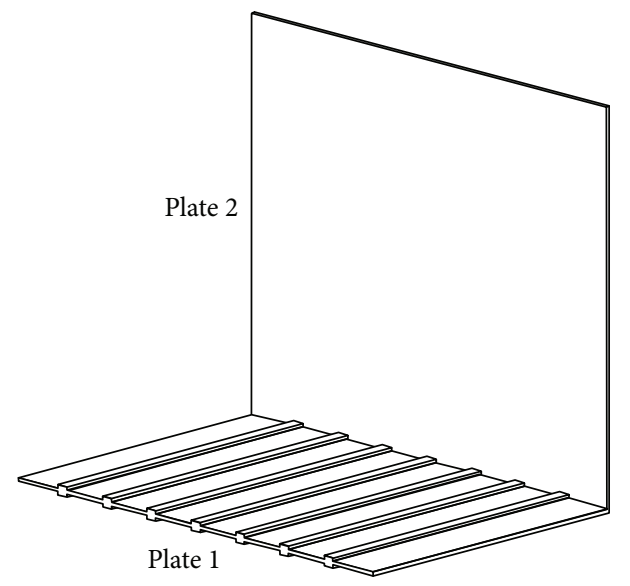

(c)

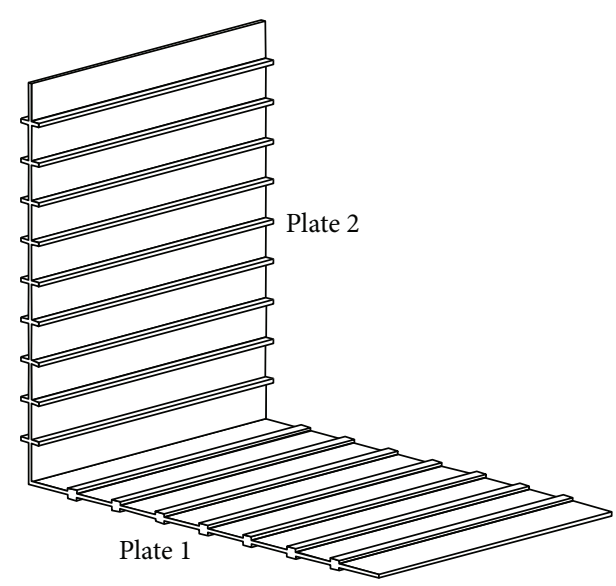

(b)

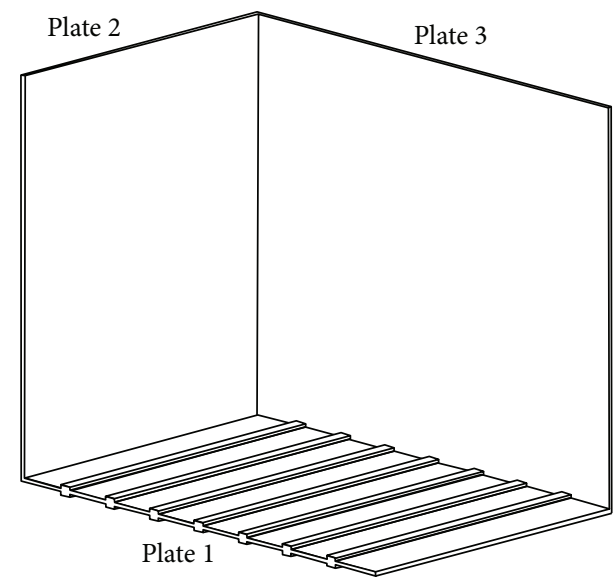

(d)

Figure 1: (a) L-junction A, (b) L-junction B, (c) L-junction C, and (d) three coupled plates.

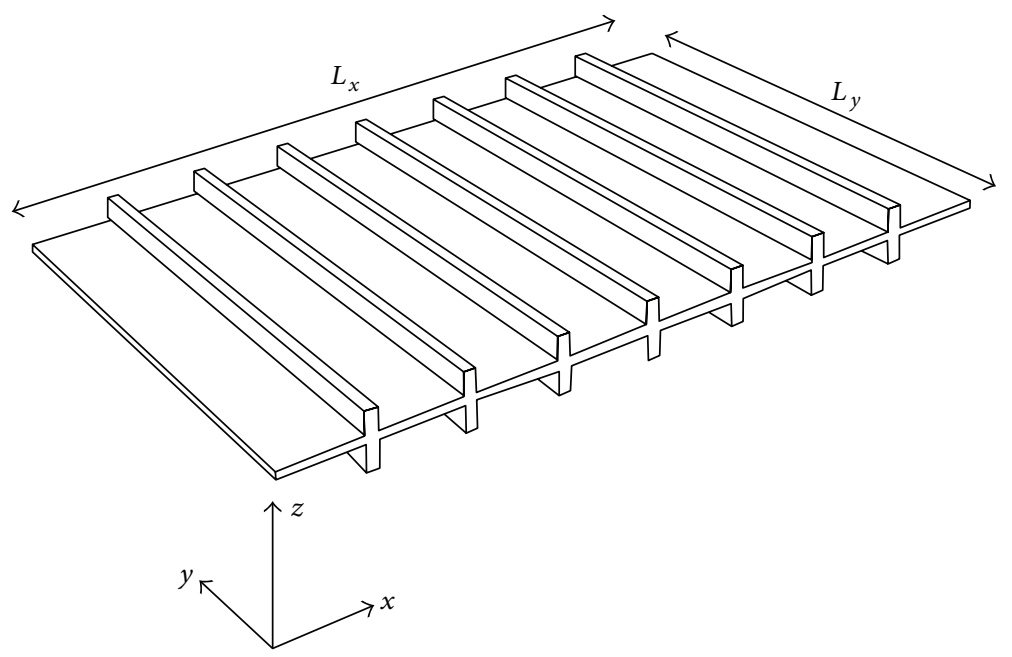

(a)

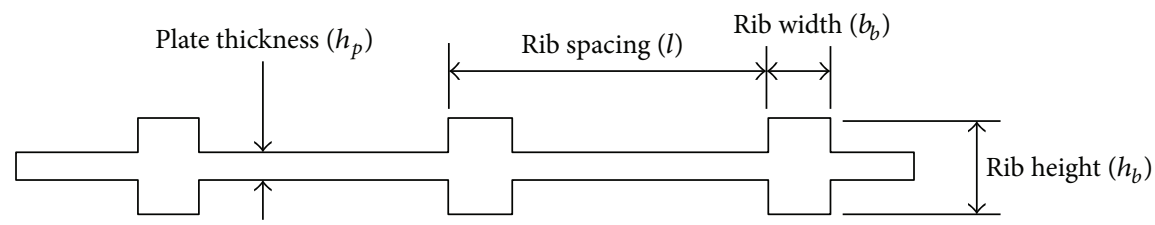

(b)

FIGURE 2: Periodic ribbed plate (a) main dimensions and (b) periodic plate parameters. 
TABLE 1: Material properties and plate dimensions.

(a)

\begin{tabular}{lccccc}
\hline & & L-junction A & L-junction B & L-junction C & Three coupled plates \\
\hline \multirow{2}{*}{ Plate 1 } & $L_{x} \times L_{y} \times h_{p}(\mathrm{~m})$ & $1.2 \times 0.8 \times 0.01$ & $1.2 \times 0.8 \times 0.01$ & $1.2 \times 0.8 \times 0.01$ & $1.2 \times 0.8 \times 0.01$ \\
& $h_{b}(\mathrm{~m})$ & $\mathrm{N} / \mathrm{A}$ & 0.025 & 0.025 & 0.025 \\
& $b_{b}(\mathrm{~m})$ & $\mathrm{N} / \mathrm{A}$ & 0.03 & 0.03 & 0.03 \\
\hline$l(\mathrm{~m})$ & $\mathrm{N} / \mathrm{A}$ & 0.15 & 0.15 & $1.0 \times 0.8 \times 0.01$ \\
Plate 2 & $L_{x} \times L_{y} \times h_{p}(\mathrm{~m})$ & $1.0 \times 0.8 \times 0.01$ & $1.0 \times 0.8 \times 0.01$ & $1.2 \times 1.0 \times 0.01$ & N/A \\
& $h_{b}(\mathrm{~m})$ & 0.06 & 0.06 & N/A & N/A \\
\hline Plate 3 & $b_{b}(\mathrm{~m})$ & 0.01 & 0.01 & N/A & N/A \\
\hline
\end{tabular}

(b)

\begin{tabular}{ccc}
\hline & Density $\left(\mathrm{kg} / \mathrm{m}^{3}\right)$ & 1218 \\
Perspex & Quasi-longitudinal phase speed $(\mathrm{m} / \mathrm{s})$ & 2045 \\
& Poisson's ratio $(-)$ & 0.3 \\
0.06
\end{tabular}

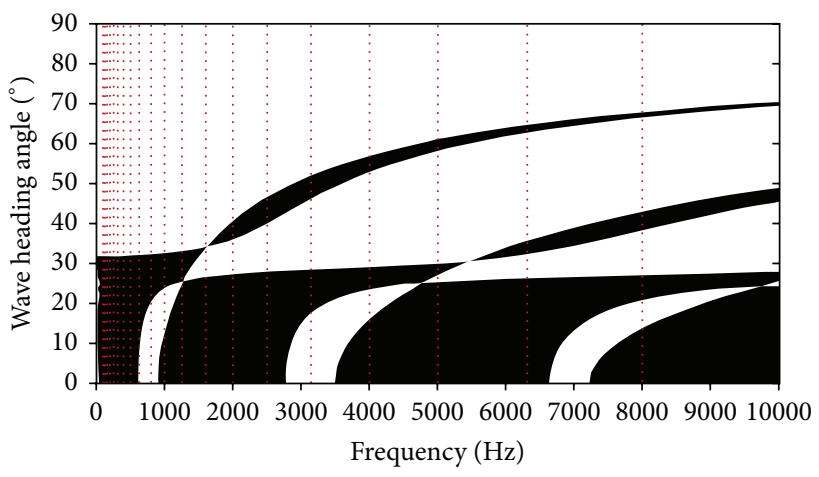

(a)

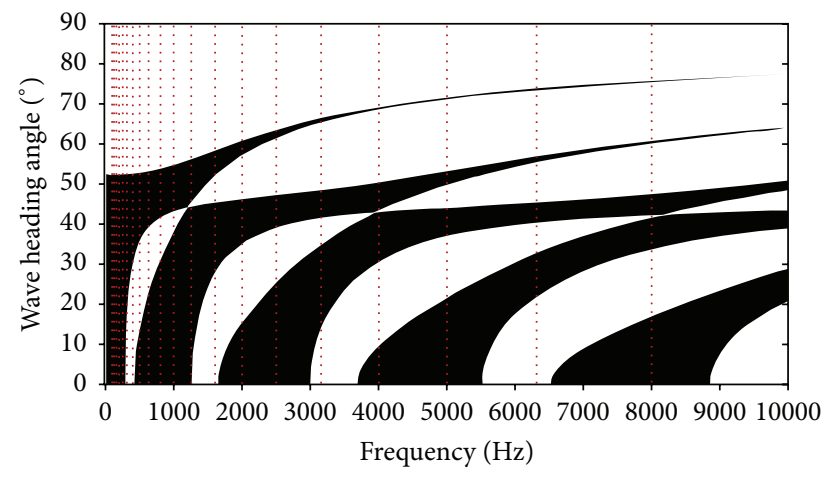

(b)

Figure 3: Propagation zones (black areas) and attenuation zones (white areas) for the periodic ribbed plate at different wave heading angles. (a) L-junctions A and B: Plate 2; (b) L-junction B: Plate 1. The red dotted lines indicate the one-third octave band centre frequencies.

nonzero real part of the propagation constant. From Figure 3 it is apparent that Plate 2 of $\mathrm{L}$-junctions $\mathrm{A}$ and $\mathrm{B}$ is distinctly different to Plate 1 of L-junction B because the propagation zones for the former are much wider and cover a smaller range of wave heading angles.

The transmission coefficients across a single rib are shown in Figure 4. This illustrates the narrow range of angles of incidence at which high transmission occurs and the large range of angles at which there is very low or zero transmission; this leads to spatial filtering with propagation over successive bays. It is seen that Plate 2 of L-junctions A and B is distinctly different to Plate 1 of L-junction B in that the former has a transmission coefficient of unity between $2 \mathrm{kHz}$ and $6 \mathrm{kHz}$ over a wide range of wave heading angles while the latter has the highest transmission coefficients (up to unity) at wave heading angles smaller than $20^{\circ}(\sin \theta=$ 0.34).

Previous work [10] showed that the vibrational energy due to bending wave motion can vary significantly between the different bays on a ribbed plate at high frequencies. This was validated by close agreement between measurements, FEM and ASEA at and above the frequency band 


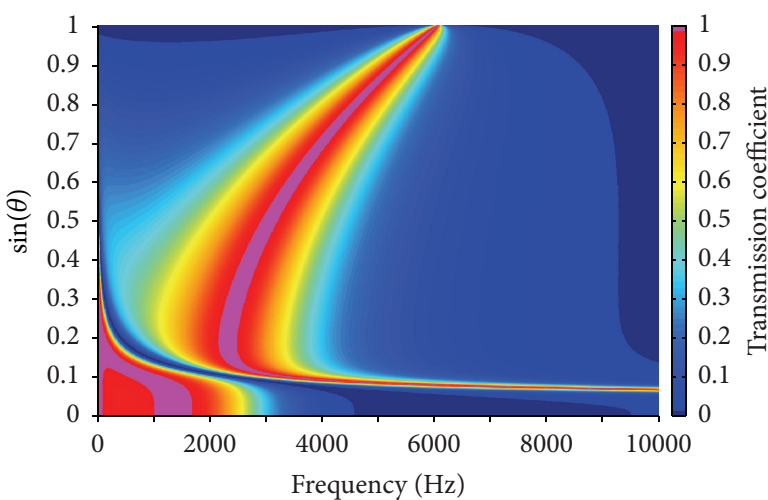

(a)

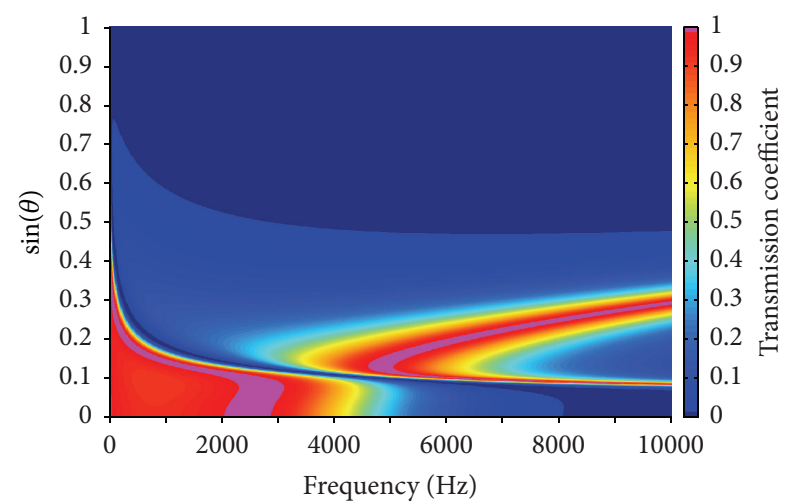

(b)

Figure 4: Transmission coefficients at different wave heading angles, $\theta$, across one rib on the periodic ribbed plates that forms (a) Plate 2 on L-junctions A and B; (b) Plate 1 on L-junction B.

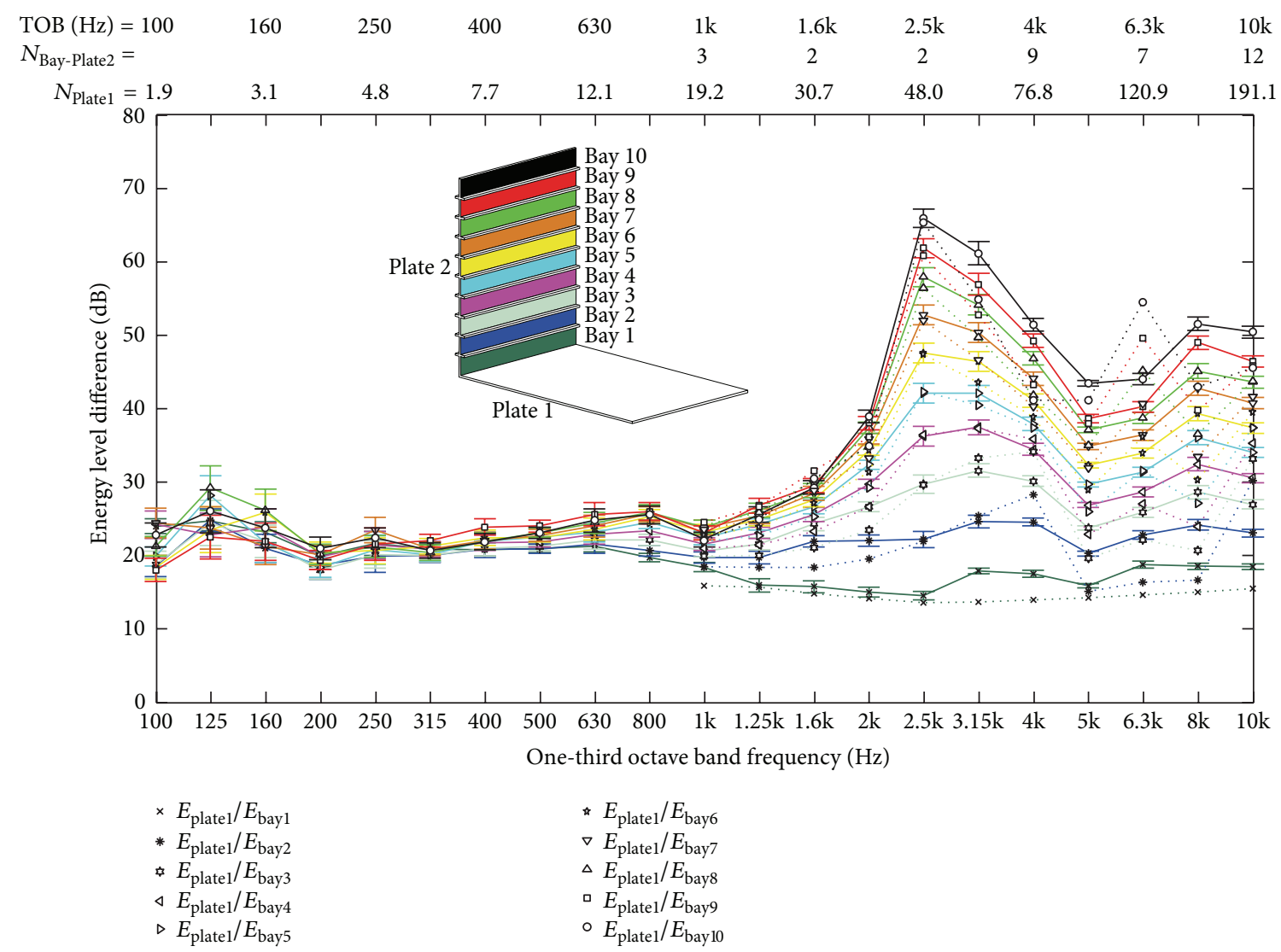

Figure 5: L-junction A. Excitation: Plate 1. Energy level differences between the isotropic, homogeneous plate (Plate 1) and each of the bays that form the periodic ribbed plate (Plate 2). Comparison between FEM and ASEA (FEM data are shown using markers with continuous lines; ASEA data are shown using markers with dotted lines). Upper $x$-axis indicates the mode counts for each bay of the ribbed plate $\left(N_{\text {Bay-Plate2 }}\right)$ and Plate $1\left(N_{\text {Platel }}\right)$.

that contains the fundamental bending mode; hence it is considered appropriate to draw conclusions in this section through the comparison of FEM with ASEA.

For L-junction A with rain-on-the-roof excitation on the isotropic plate (Plate 1), Figure 5 shows FEM and ASEA energy level differences between Plate 1 and each of the bays that form ribbed Plate 2. Between $100 \mathrm{~Hz}$ and $1 \mathrm{kHz}$ the FEM data shows that the variation in response between all the bays is $\leq 6.5 \mathrm{~dB}$; this variation is sufficiently low that it would not be appropriate to model the bays as individual 


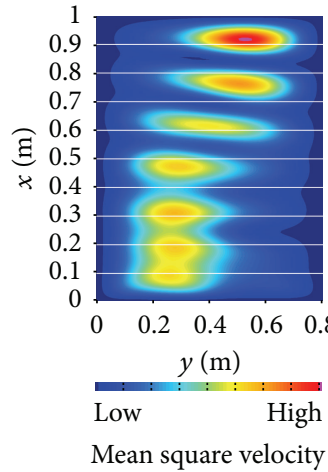

(a) $315 \mathrm{~Hz}$

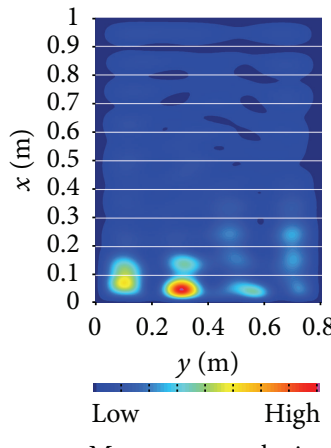

Mean square velocity

(e) $800 \mathrm{~Hz}$

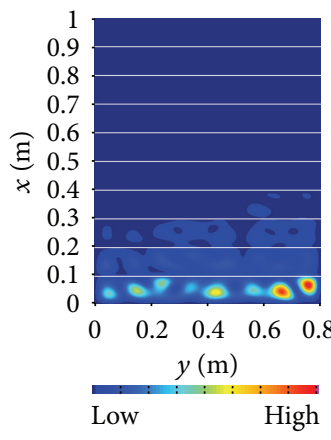

Mean square velocity

(i) $2 \mathrm{kHz}$

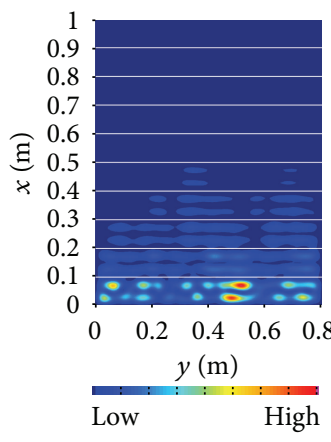

Mean square velocity

(m) $5 \mathrm{kHz}$

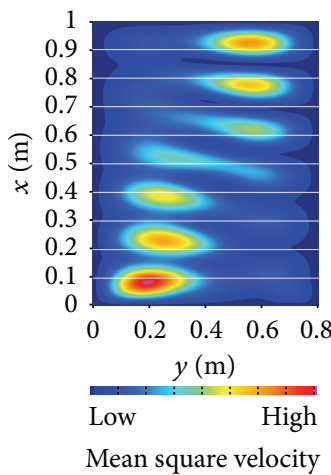

(b) $400 \mathrm{~Hz}$

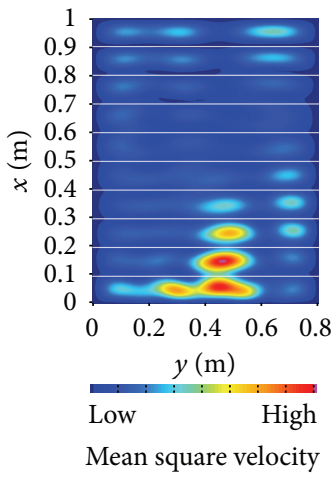

(f) $1 \mathrm{kHz}$

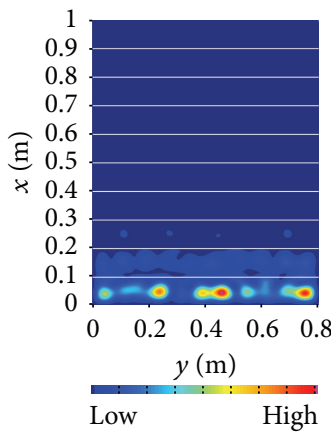

Mean square velocity

(j) $2.5 \mathrm{kHz}$

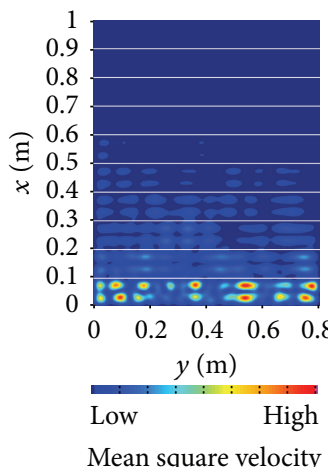

(n) $6.3 \mathrm{kHz}$

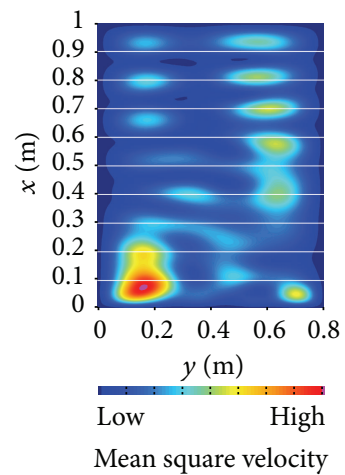

(c) $500 \mathrm{~Hz}$

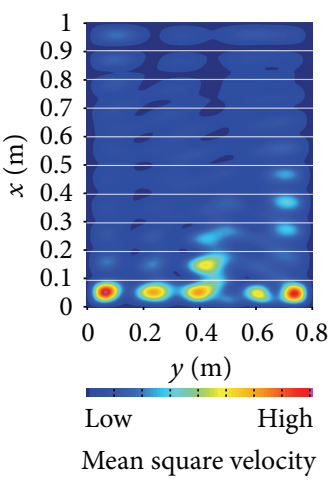

(g) $1.25 \mathrm{kHz}$

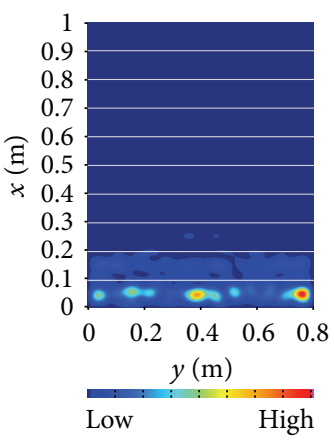

Mean square velocity

(k) $3.15 \mathrm{kHz}$

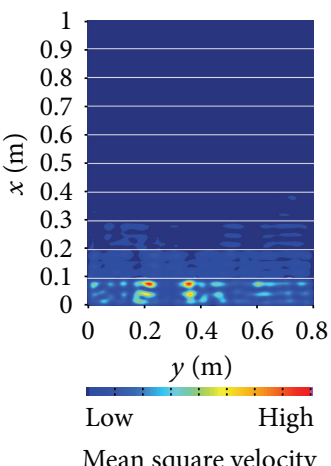

(o) $8 \mathrm{kHz}$

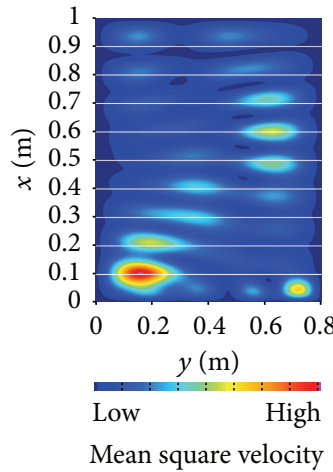

(d) $630 \mathrm{~Hz}$

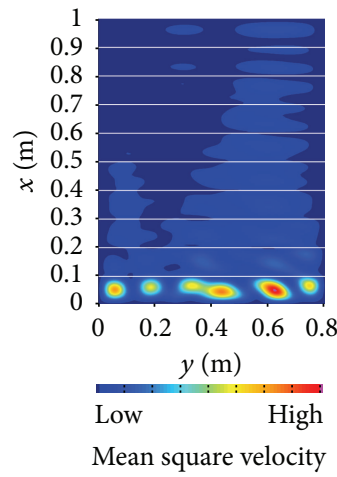

(h) $1.6 \mathrm{kHz}$

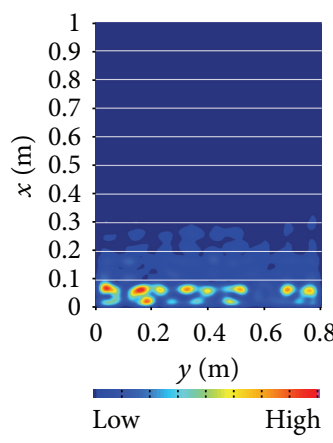

Mean square velocity

(l) $4 \mathrm{kHz}$

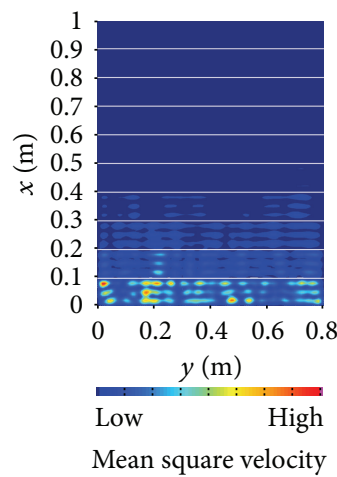

(p) $10 \mathrm{kHz}$

Figure 6: L-junction A. Mean-square vibration over the surface of the periodic ribbed plate (Plate 2) in one-third octave bands between $315 \mathrm{~Hz}$ and $10 \mathrm{kHz}$ with excitation on Plate 1. 


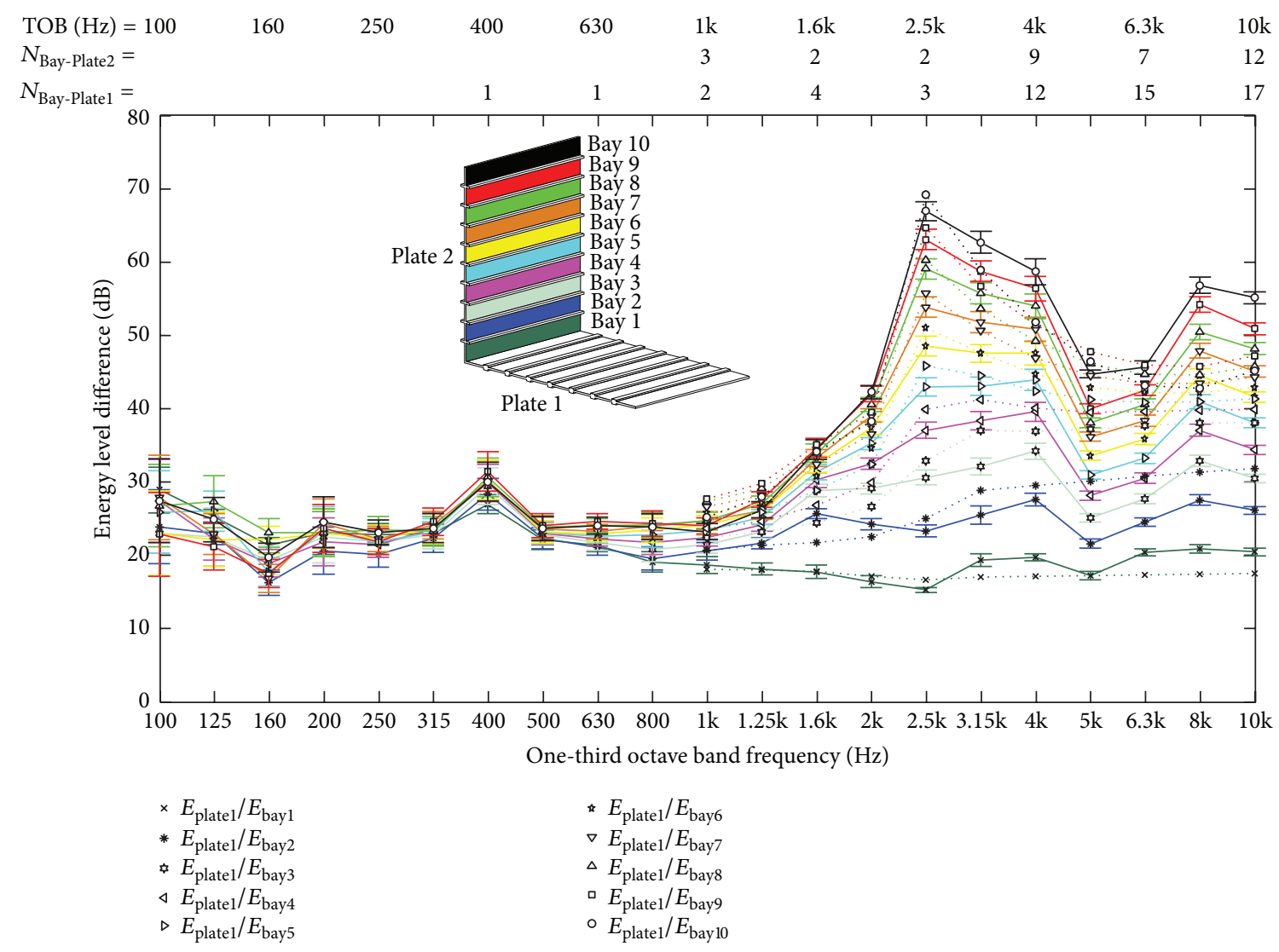

Figure 7: L-junction B. Excitation: Plate 1. Energy level differences between the periodic ribbed plate (Plate 1) and each of the bays that form the other periodic ribbed plate (Plate 2). Comparison between FEM and ASEA (FEM data are shown using markers with continuous lines; ASEA data are shown using markers with dotted lines). Upper $x$-axis indicates the mode counts for each bay of the ribbed plates $\left(N_{\text {Bay-Platel }}\right.$

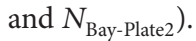

subsystems. However, between $1 \mathrm{kHz}$ and $10 \mathrm{kHz}$ each bay can support local bending modes and the difference in the FEM response between adjacent bays ranges from $10 \mathrm{~dB}$ to $56 \mathrm{~dB}$. In this high-frequency range there is reasonable agreement between FEM and ASEA. The significant decrease in response across successive bays between $2 \mathrm{kHz}$ and $3.15 \mathrm{kHz}$ can be interpreted with reference to the propagation and attenuation zones in Figure 3(a) and the transmission coefficients in Figure 4(a). Between $2 \mathrm{kHz}$ and $3.15 \mathrm{kHz}$ there is a zone where the transmission coefficient is in-between high transmission peaks and this essentially means that a bending wave cannot propagate across the ribbed plate therefore resulting in a peak in energy level difference.

Figure 6 shows the mean-square velocity over the surface of the ribbed plate with excitation on the isotropic plate (Plate 1). This is shown in one-third octave bands that are calculated from FEM data at individual frequencies. The contour plots indicate that the crossover from the modal response of the entire ribbed plate to modes in individual bays appears to occur in the $800 \mathrm{~Hz}$ band. By assuming simply supported boundaries, the local bending mode of each bay is estimated to fall in the $1 \mathrm{kHz}$ rather than the $800 \mathrm{~Hz}$ band; however this approach provides a reasonable estimate. Above $1 \mathrm{kHz}$
Figure 6 also shows that the highest levels of bending wave energy are in bay 1 that is closest to the junction line. Note that this effect is not attributed to Anderson localisation [16] on an "imperfectly periodic" structure because this is expected to occur with one-dimensional systems [17] and also the FEM model represents a "perfectly periodic" ribbed plate. The close agreement between FEM and ASEA in Figure 5 confirms that the decrease in vibration across successive bays of the ribbed plate can be described purely by accounting for spatial filtering and propagation losses in ASEA.

L-junction B comprises two ribbed plates for which the energy level differences are shown in Figures 7 and 8 when rain-on-the-roof excitation is applied over all the bays of Plates 1 and 2, respectively. When the source plate is Plate 1 , the variation in the FEM response between all the bays on the receiving plate (Plate 2) is $\leq 5.5 \mathrm{~dB}$ from $100 \mathrm{~Hz}$ to $1 \mathrm{kHz}$ (i.e., below the fundamental bending mode of each bay on Plate 2). When the source plate is Plate 2, the difference in response between all the bays on the receiving plate (Plate 1) is $\leq 5 \mathrm{~dB}$ from $100 \mathrm{~Hz}$ to $400 \mathrm{~Hz}$ (i.e., below the fundamental bending mode of each bay on Plate 1) and $\leq 6.5 \mathrm{~dB}$ from $400 \mathrm{~Hz}$ to $1 \mathrm{kHz}$. When a ribbed plate is the 


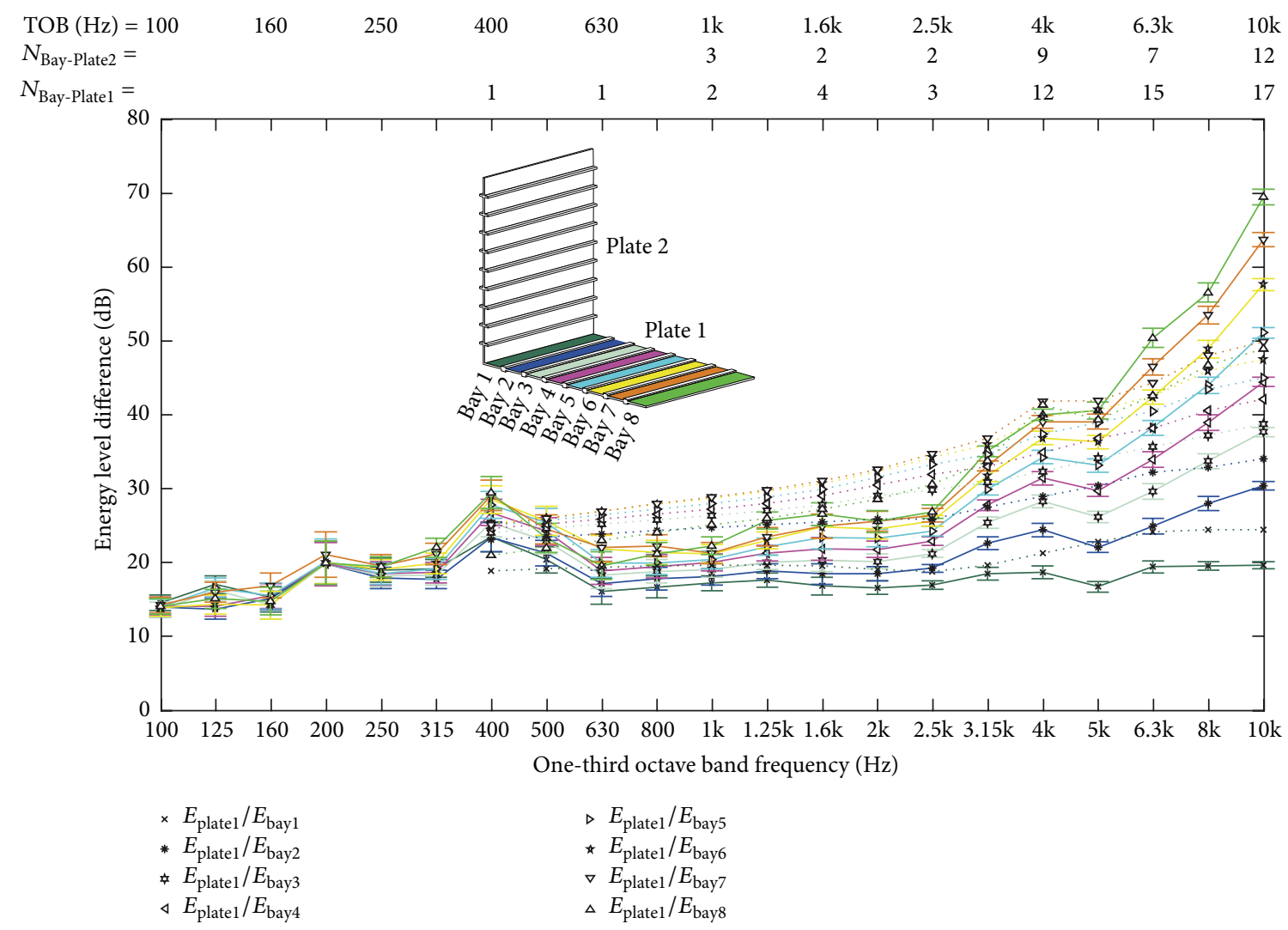

FiguRE 8: L-junction B. Excitation: Plate 2. Energy level differences between the periodic ribbed plate (Plate 2) and each of the bays that form the other periodic ribbed plate (Plate 1). Comparison between FEM and ASEA (FEM data are shown using markers with continuous lines; ASEA data are shown using markers with dotted lines). Upper $x$-axis indicates the mode counts for each bay of the ribbed plates $\left(N_{\text {Bay-Platel }}\right.$ and $N_{\text {Bay-Plate2 }}$ ).

receiving subsystem it is concluded that (a) it is appropriate to represent it as a single SEA subsystem at frequencies below the fundamental bending mode of each bay and (b) above the fundamental bending mode of each bay there can be a significant decrease in the vibration level across successive bays in certain frequency ranges that are described by ASEA and (c) above the fundamental bending mode of each bay there is reasonable agreement between FEM and ASEA (although above $5 \mathrm{kHz}$ there is less agreement for the few bays that are furthest from the junction).

The above evidence shows that ASEA can describe the spatial variation in vibration across the bays of the ribbed plate above the fundamental bending mode of each bay. However, one of the strengths of SEA is that it can predict the spatial average response on a subsystem. Hence the next step is to compare the energy level differences from FEM against (a) SEA where the ribbed plate is modelled as a single subsystem and (b) ASEA where the predicted response in all of the bays on each ribbed plate is averaged to give a spatial average response for each ribbed plate. These results are shown in Figures 9 and 10 for L-junctions $A$ and B, respectively. For $\mathrm{L}$-junctions $\mathrm{A}$ and $\mathrm{B}$, there is reasonable agreement between FEM, SEA, and ASEA between $100 \mathrm{~Hz}$ and $10 \mathrm{kHz}$. The agreement between FEM and SEA incorporating Bloch theory is noteworthy because the latter is computationally more efficient. However, Figures 5, 7, and 8 show that, above the fundamental bending mode of each bay, the difference in the response between the bay closest to the junction and the bay furthest from the junction is up to $56 \mathrm{~dB}$. Therefore a spatial average value for the response of the ribbed plate is not particularly helpful or meaningful when interpreting the results. For example, SEA would not indicate to the noise control engineer that damping material on the receiving plate would be most efficient if applied to the bays closest to the junction rather than being distributed across all bays.

For L-junctions A and B, the ASEA prediction is within $2.5 \mathrm{~dB}$ of the SEA prediction in the frequency band containing the fundamental bending mode of each bay (i.e., $1 \mathrm{kHz}$ for L-junction $\mathrm{A}$ and $400 \mathrm{~Hz}$ for $\mathrm{L}$-junction $\mathrm{B}$ ). The only exception to this is when the source plate is Plate 2 for Ljunction $\mathrm{B}$ where the difference between ASEA and SEA in the $400 \mathrm{~Hz}$ band is $5 \mathrm{~dB}$. Hence it is proposed here that SEA is used at low frequencies below the fundamental bending mode of each bay. For the crossover from SEA to ASEA it is proposed that, in the frequency band which contains 

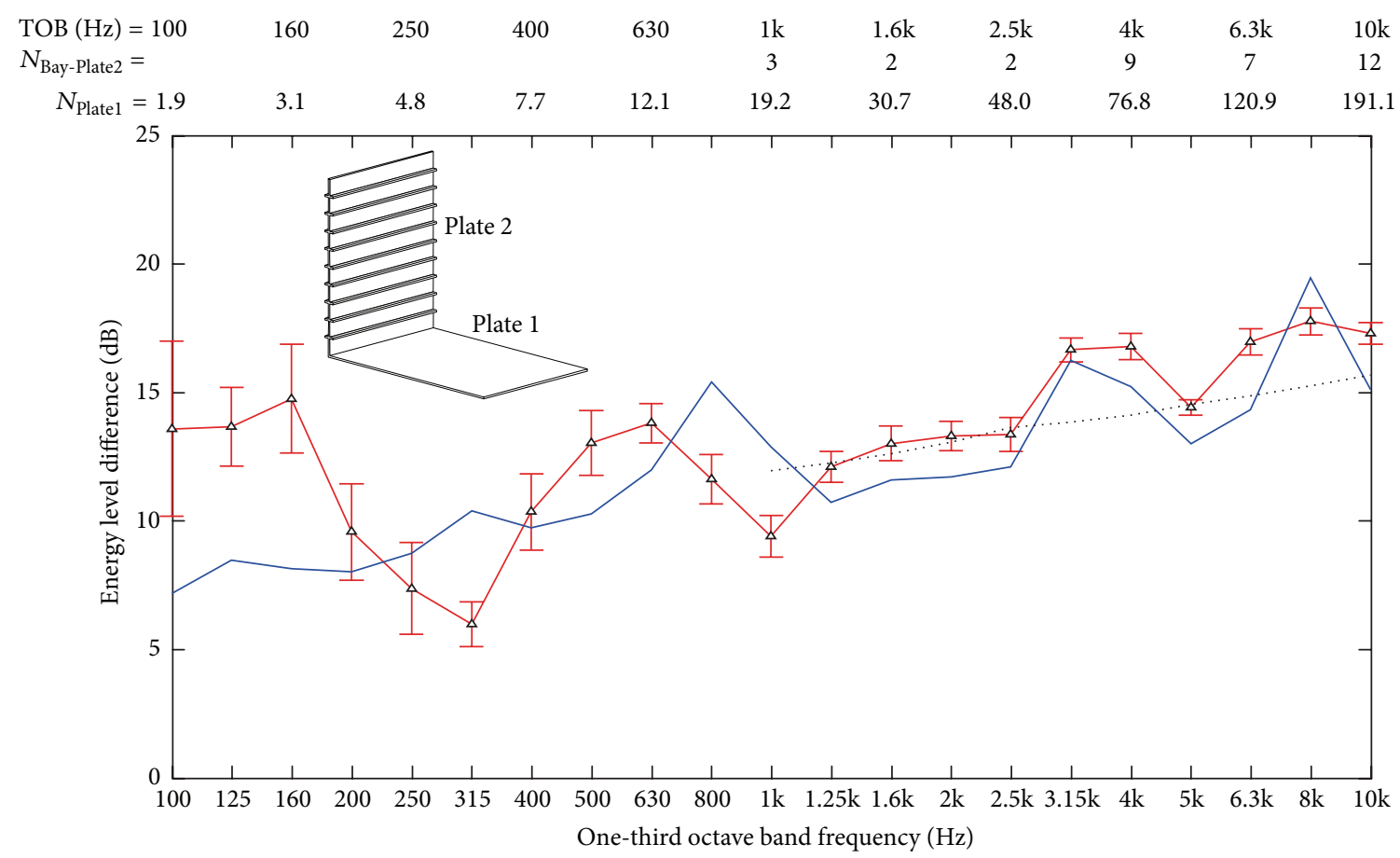$$
\begin{array}{ll}
\triangle & E_{1} / E_{2}: \text { FEM } \\
- & E_{1} / E_{2}: \text { SEA } \\
\cdots & E_{1} / E_{2}: \text { ASEA }
\end{array}
$$

\begin{tabular}{|c|c|c|c|c|c|c|c|c|c|c|}
\hline $\mathrm{TOB}(\mathrm{Hz})=100$ & 160 & 250 & 400 & 630 & $1 \mathrm{k}$ & $1.6 \mathrm{k}$ & $2.5 \mathrm{k}$ & $4 \mathrm{k}$ & $6.3 \mathrm{k}$ & $10 \mathrm{k}$ \\
\hline$N_{\text {Bay-Plate2 }}=$ & & & & & 3 & 2 & 2 & 9 & 7 & 12 \\
\hline$N_{\text {Plate1 }}=1.9$ & 3.1 & 4.8 & 7.7 & 12.1 & 19.2 & 30.7 & 48.0 & 76.8 & 120.9 & 191.1 \\
\hline
\end{tabular}

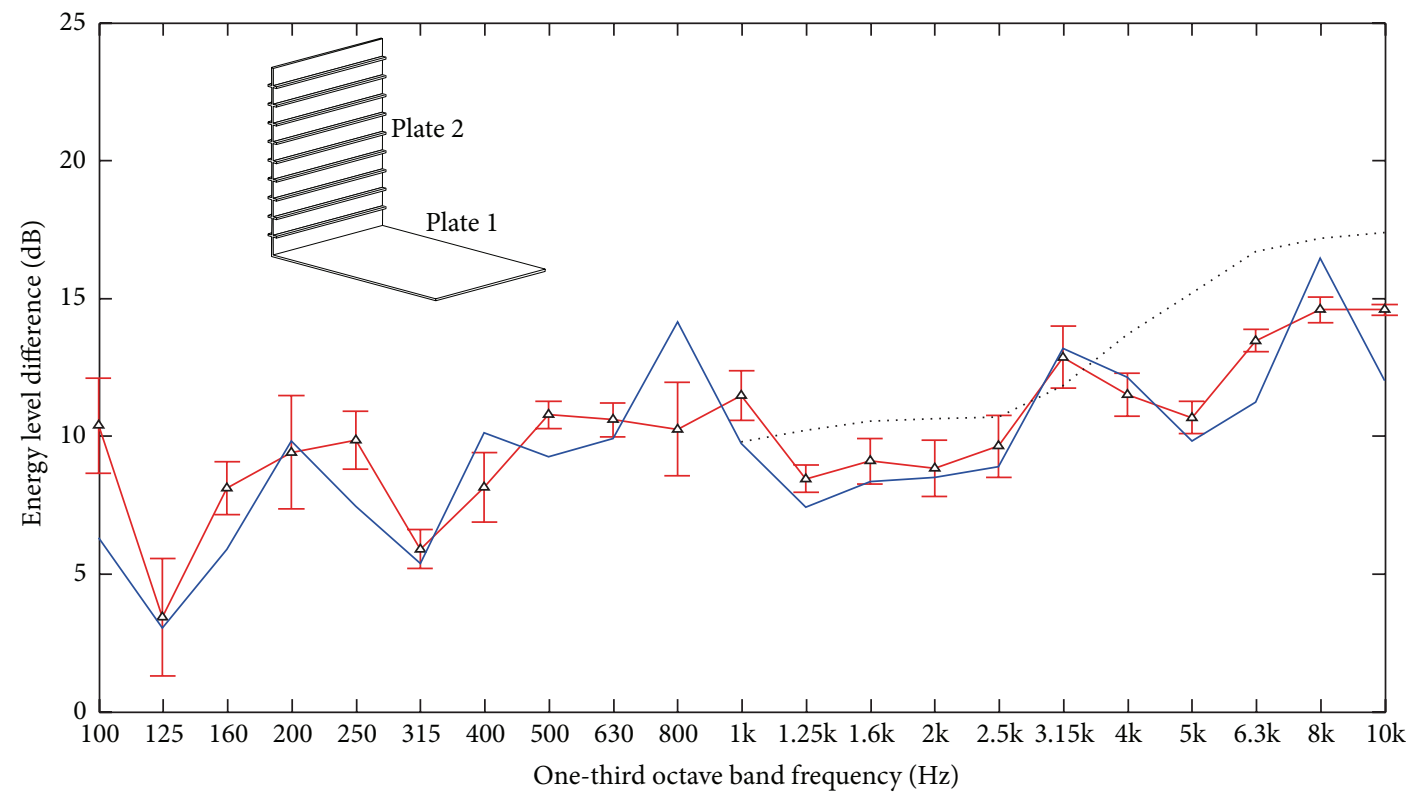

$\begin{array}{ll}\triangle & E_{2} / E_{1}: \text { FEM } \\ - & E_{2} / E_{1}: \text { SEA } \\ \cdots & E_{2} / E_{1}: \text { ASEA }\end{array}$

(b)

Figure 9: L-junction A. Energy level differences between the isotropic, homogeneous plate (Plate 1) and periodic ribbed plate (Plate 2) with excitation of (a) Plate 1 and (b) Plate 2. 

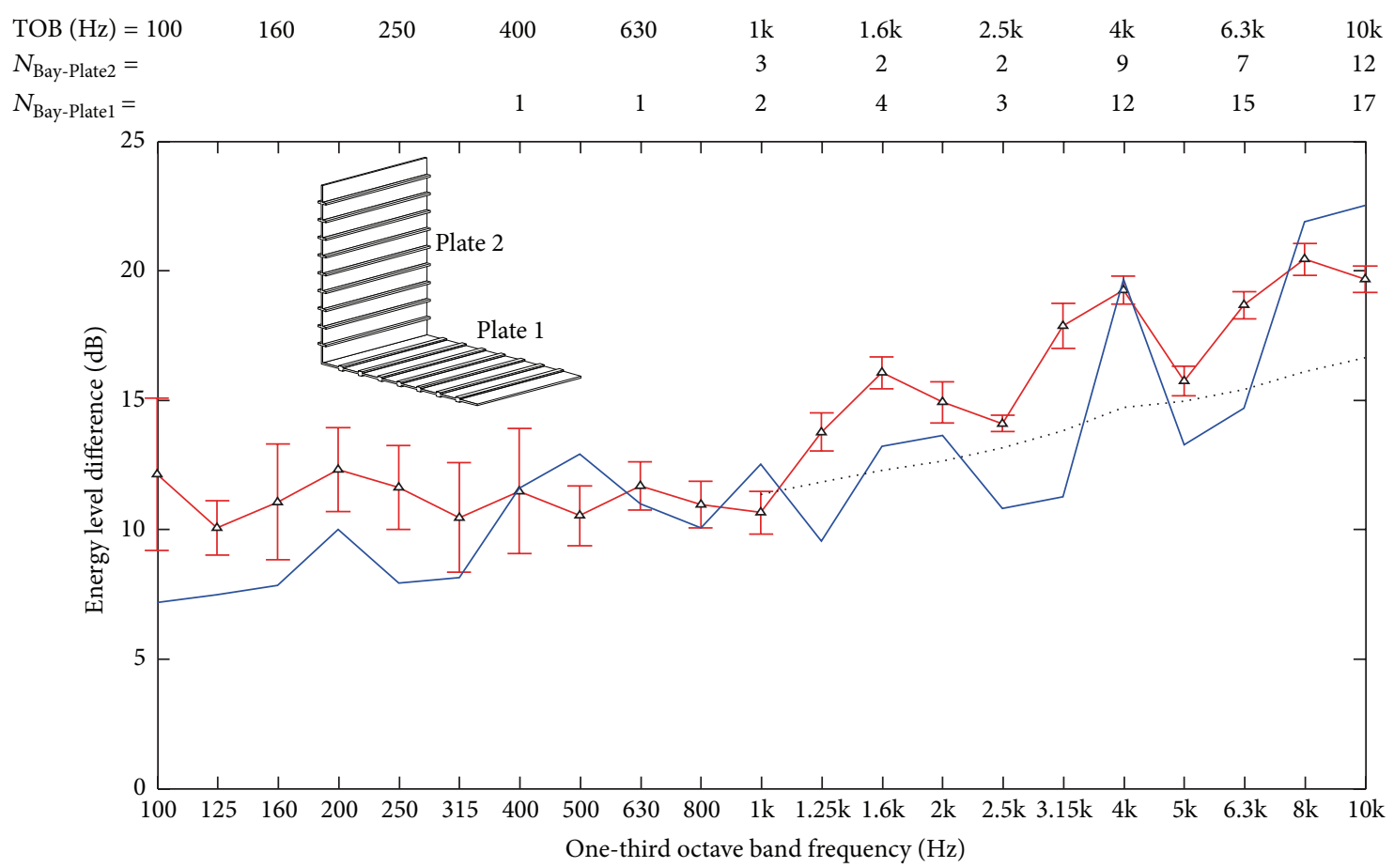

$\begin{array}{ll}\triangle & E_{1} / E_{2}: \text { FEM } \\ - & E_{1} / E_{2}: \text { SEA } \\ \cdots \cdots & E_{1} / E_{2}: \text { ASEA }\end{array}$

(a)

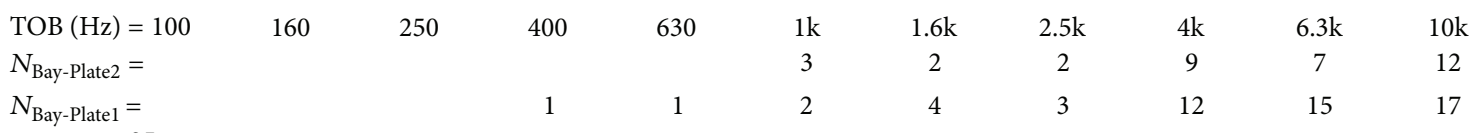

$N_{\text {Bay-Platel }}=\quad \begin{array}{lllllllll}1 & 1 & 2 & 4 & 3 & 12 & 15 & 17\end{array}$

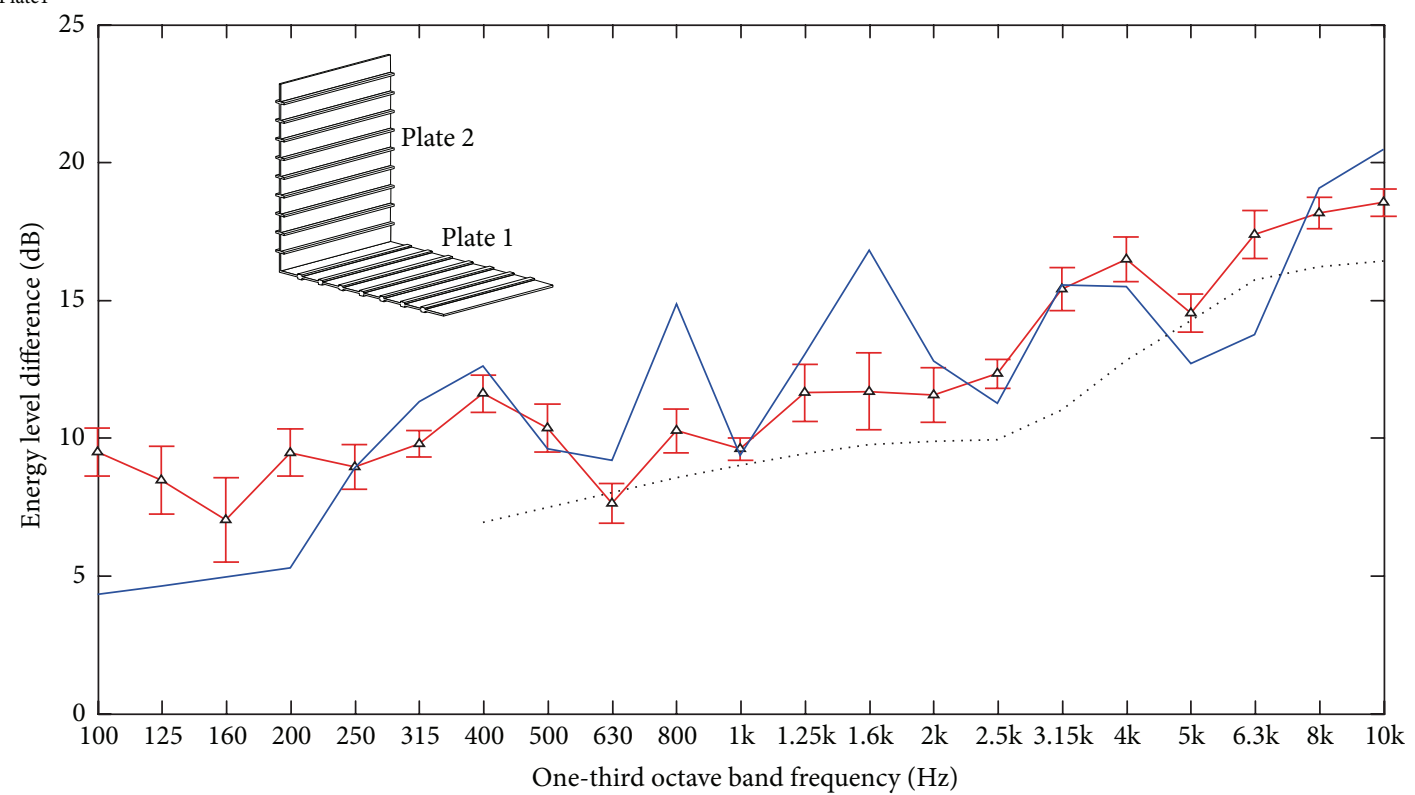

$\begin{array}{ll}\rightarrow- & E_{2} / E_{1}: \text { FEM } \\ - & E_{2} / E_{1}: \text { SEA } \\ \cdots & E_{2} / E_{1}: \text { ASEA }\end{array}$

(b)

Figure 10: L-junction B. Energy level differences between the isotropic, homogeneous plate (Plate 1) and the periodic ribbed plate (Plate 2) with excitation of (a) Plate 1 and (b) Plate 2. 

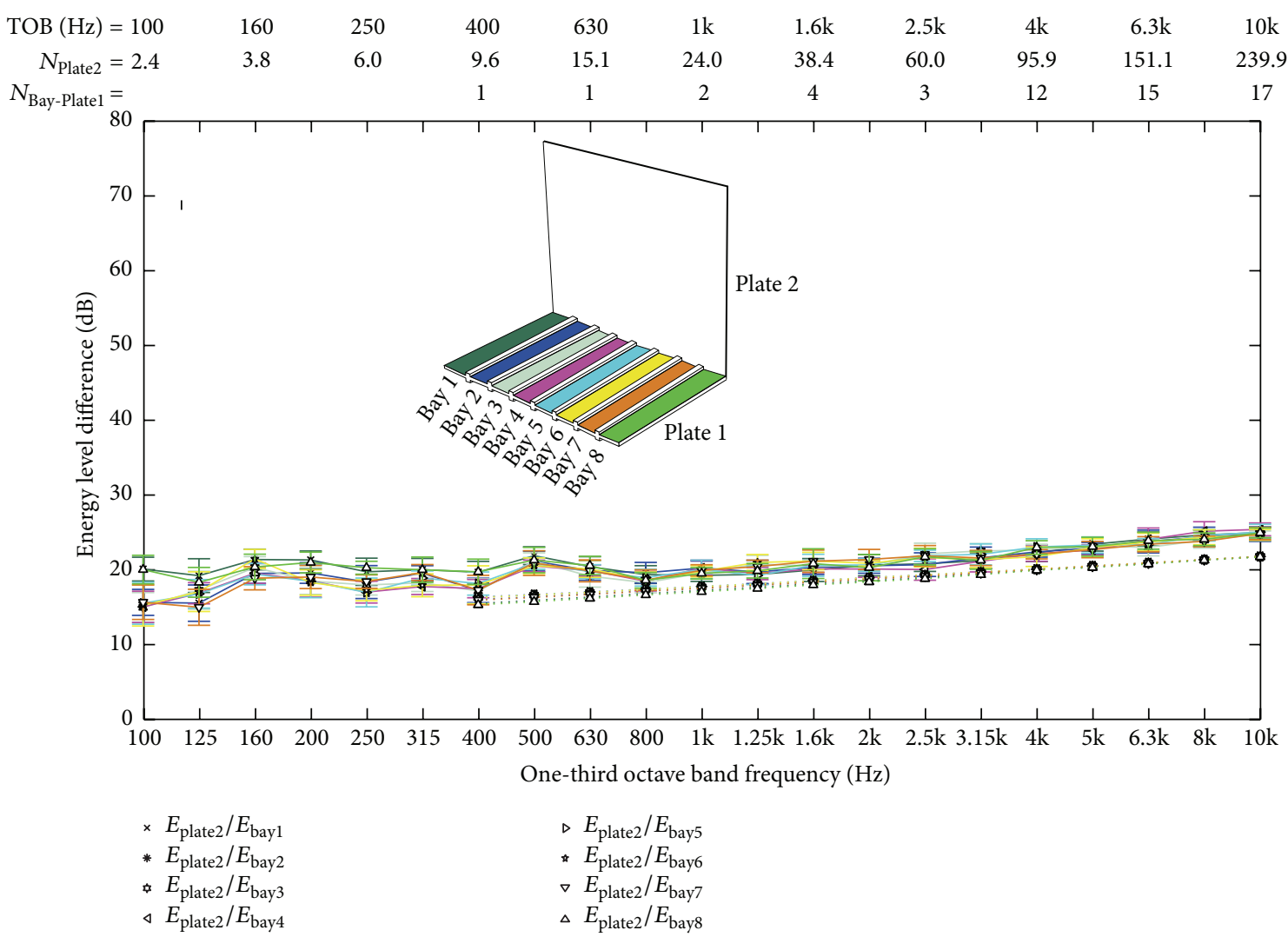

FIGURE 11: L-junction C. Excitation: Plate 2. Energy level differences between the isotropic plate (Plate 2) and each of the bays that form the other periodic ribbed plate (Plate 1). Comparison between FEM and ASEA (FEM data are shown using markers with continuous lines; ASEA data are shown using markers with dotted lines). Upper $x$-axis indicates the mode counts for each bay of the ribbed plate $\left(N_{\text {Bay-Platel }}\right)$ and Plate $2\left(N_{\text {Plate2 }}\right)$.

the fundamental bending mode of each bay, the predicted values from SEA and ASEA can be averaged to improve the crossover between the two models. In higher frequency bands, ASEA can be used to predict the response in individua bays.

3.2. L-Junction $C$ (Ribs Perpendicular to the Junction). Figure 11 shows FEM and ASEA energy level differences between Plate 2 and each of the bays that form ribbed Plate 1. The response predicted by FEM in all the bays is similar across the entire frequency range, with FEM and ASEA showing reasonable agreement between $400 \mathrm{~Hz}$ and $10 \mathrm{kHz}$; hence whilst spatial filtering is not apparent in this case, ASEA is appropriate to predict the response in individual bays.

Figure 12 shows the energy level differences predicted using FEM, SEA, and ASEA where the SEA model represents the ribbed plate as a single subsystem with angle-dependent bending stiffness. When the source is ribbed Plate 1 , close agreement is seen between FEM, SEA, and ASEA between $500 \mathrm{~Hz}$ and $10 \mathrm{kHz}$ (i.e., where the bays support local bending modes) with reasonable agreement at lower frequencies. When the source plate is isotropic Plate 2, close agreement is also seen between FEM and SEA from $500 \mathrm{~Hz}$ to $10 \mathrm{kHz}$; however, ASEA tends to overestimate the response predicted by FEM on the receiving plate up to a maximum of $4 \mathrm{~dB}$ at $10 \mathrm{kHz}$.

3.3. Three Coupled Plates. For rain-on-the-roof excitation on isotropic Plates 2 and 3, Figures 13 and 14 each show FEM and ASEA predictions of the energy level differences between (a) the source plate and each of the bays that form ribbed Plate 1 and (b) the source plate and the other isotropic plate. With excitation on Plate 2 (Figure 13) the energy level differences above $400 \mathrm{~Hz}$ increase across successive bays on Plate 1 that are further away from the junction between Plates 1 and 2 . Hence even when there is flanking transmission from Plate 2 via Plate 3 to the bays of Plate 1 it is still necessary to use ASEA to predict the response on the bays. However, with excitation on Plate 3 (Figure 14) the dominant transmission path is from Plate 3 to the bays on Plate 1; hence all bays have similar energy.

Figures 15, 16, and 17 show the energy level differences predicted using FEM, SEA, and ASEA when the SEA model uses Bloch theory to determine the coupling between Plates 1 and 2 but treats the ribbed plate as a single subsystem with angle-dependent bending stiffness to determine the coupling 


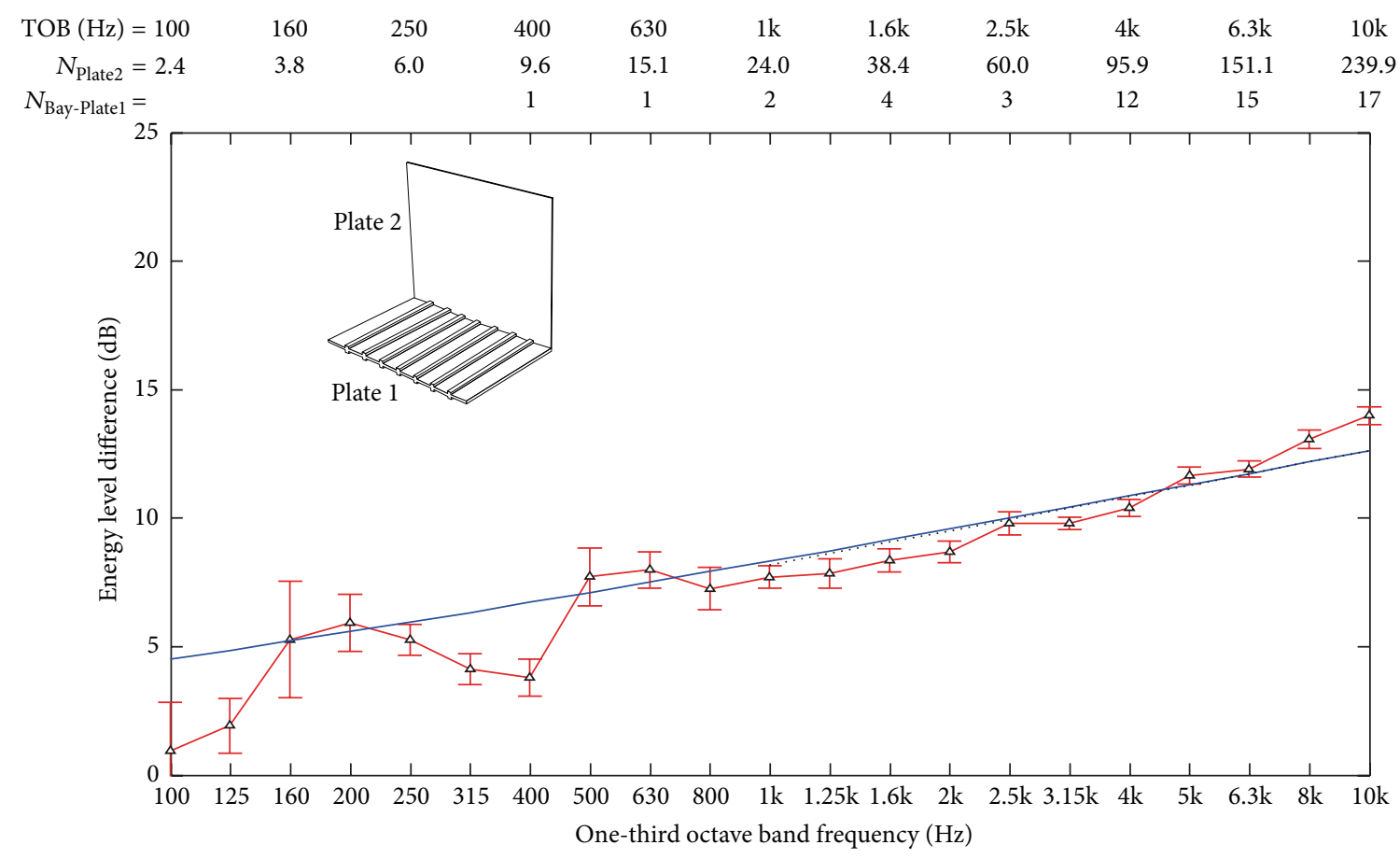

$\begin{array}{ll}\triangle & E_{1} / E_{2}: \text { FEM } \\ - & E_{1} / E_{2}: \text { SEA } \\ \cdots & E_{1} / E_{2}: \text { ASEA }\end{array}$

\begin{tabular}{|c|c|c|c|c|c|c|c|c|c|c|}
\hline $\mathrm{TOB}(\mathrm{Hz})=100$ & 160 & 250 & 400 & 630 & $1 \mathrm{k}$ & $1.6 \mathrm{k}$ & $2.5 \mathrm{k}$ & $4 \mathrm{k}$ & $6.3 \mathrm{k}$ & $10 \mathrm{k}$ \\
\hline$N_{\text {Plate2 }}=2.4$ & 3.8 & 6.0 & 9.6 & 15.1 & 24.0 & 38.4 & 60.0 & 95.9 & 151.1 & 239.9 \\
\hline$N_{\text {Bay-Platel }}=$ & & & 1 & 1 & 2 & 4 & 3 & 12 & 15 & 17 \\
\hline
\end{tabular}

\begin{tabular}{ll}
17 \\
\hline
\end{tabular}

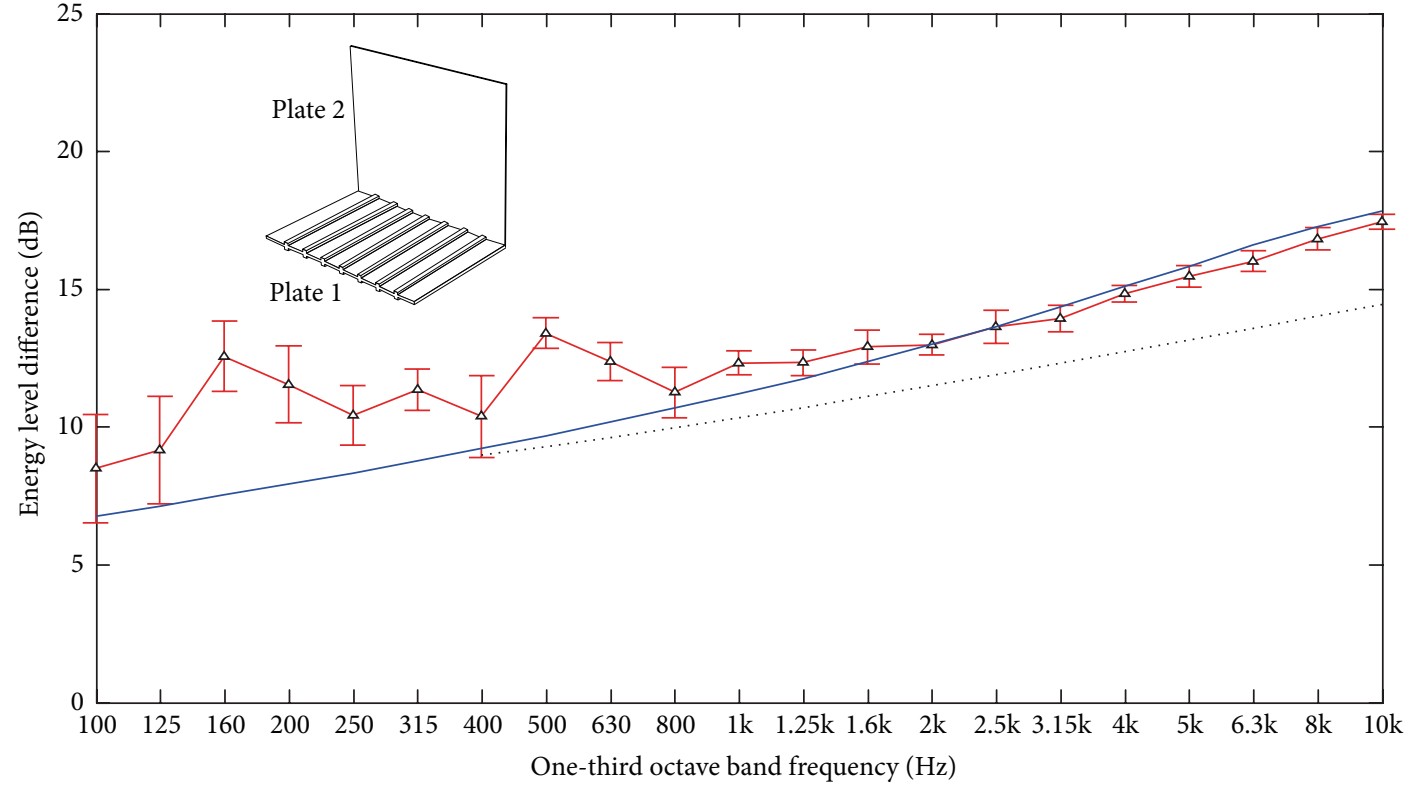

$$
\begin{array}{ll}
\rightarrow & E_{2} / E_{1}: \text { FEM } \\
- & E_{2} / E_{1}: \text { SEA } \\
\cdots \cdots & E_{2} / E_{1}: \text { ASEA }
\end{array}
$$

(b)

FIGURE 12: L-junction C. Energy level differences between the isotropic, homogeneous plate (Plate 1) and the periodic ribbed plate (Plate 2) with excitation of (a) Plate 1 and (b) Plate 2. 


\begin{tabular}{rlcccccccccc} 
TOB $(\mathrm{Hz})$ & $=100$ & 160 & 250 & 400 & 630 & $1 \mathrm{k}$ & $1.6 \mathrm{k}$ & $2.5 \mathrm{k}$ & $4 \mathrm{k}$ & $6.3 \mathrm{k}$ & $10 \mathrm{k}$ \\
$N_{\text {Plate3 }}$ & $=2.4$ & 3.8 & 6.0 & 9.6 & 15.1 & 24.0 & 38.4 & 60.0 & 95.9 & 151.1 & 239.9 \\
$N_{\text {Plate2 }}$ & $=1.6$ & 2.6 & 4.0 & 6.4 & 10.1 & 16.0 & 25.6 & 40.0 & 64.0 & 100.7 & 159.9 \\
$N_{\text {Bay-Plate1 }}$ & $=$ & & & 1 & 1 & 2 & 4 & 3 & 12 & 15 & 17 \\
\hline
\end{tabular}

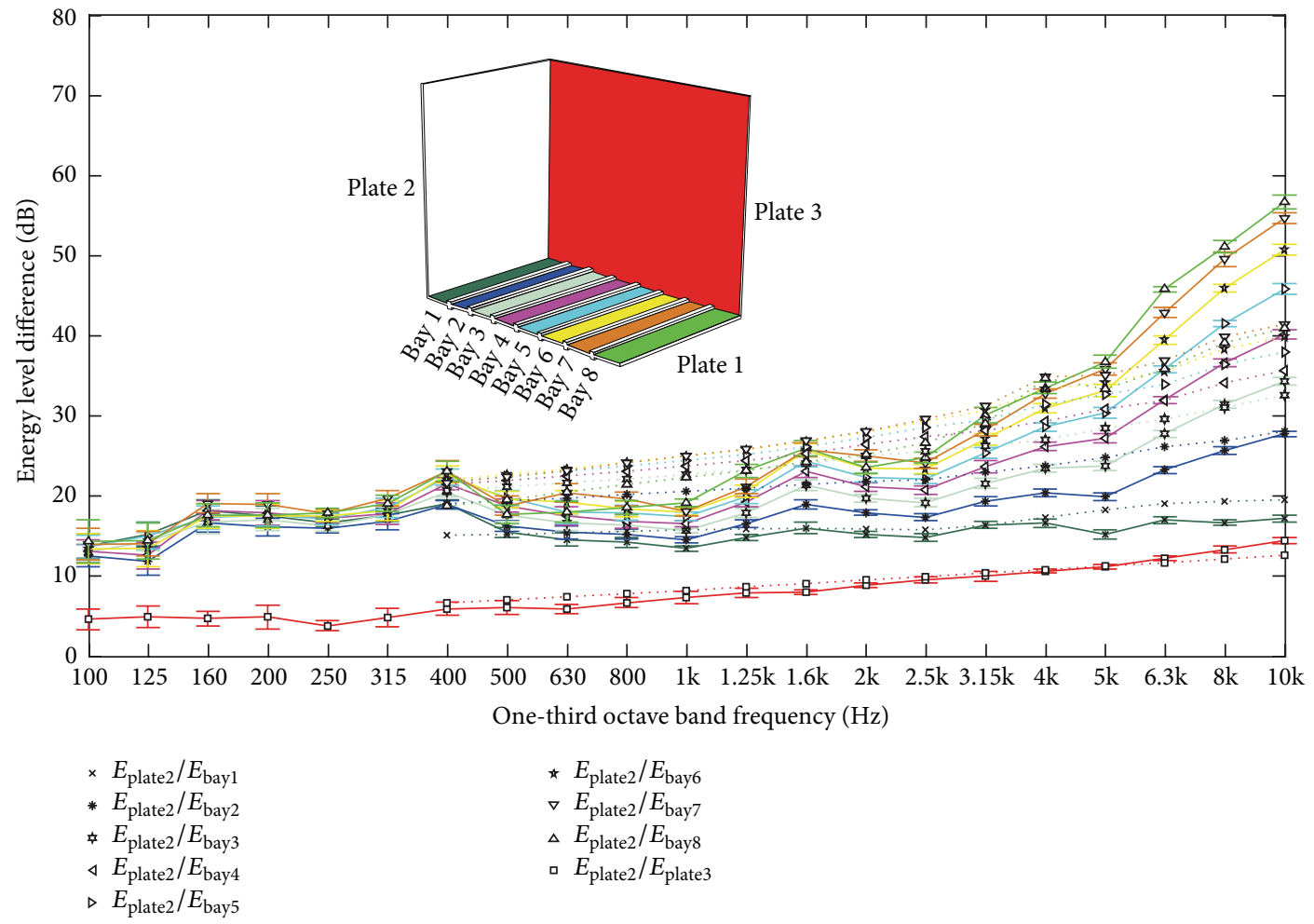

Figure 13: Three coupled plates. Excitation: Plate 2. Energy level differences between the isotropic plate (Plate 2) and each of the bays that form the other periodic ribbed plate (Plate 1) as well as the other isotropic plate (Plate 3). Comparison between FEM and ASEA (FEM data are shown using markers with continuous lines; ASEA data are shown using markers with dotted lines).

between Plates 1 and 3. When the source is ribbed Plate 1 or isotropic Plate 2, there is close agreement between FEM, SEA, and ASEA between $100 \mathrm{~Hz}$ and $10 \mathrm{kHz}$. When the source is isotropic Plate 3, there is close agreement between SEA and FEM between $400 \mathrm{~Hz}$ and $10 \mathrm{kHz}$ with reasonable agreement at lower frequencies; however (as expected from the analysis in Section 3.2) ASEA tends to overestimate the response on the receiving plate up to a maximum of $3.7 \mathrm{~dB}$ at $10 \mathrm{kHz}$.

\section{Conclusions}

For L-junctions comprised of one or two periodic ribbed plates, this paper investigated the crossover from an SEA model for the low- and mid-frequency ranges to an ASEA model for the high-frequency range. Numerical experiments with FEM provided the benchmark upon which the SEA and ASEA models were assessed. The results confirmed that the crossover occurs in the vicinity of the fundamental bending mode of the individual bays on the ribbed plate when the ribs are parallel to the junction line.

Below the frequency band in which the bays of the ribbed receiving plate support local bending modes, an
SEA model was used which treated each periodic ribbed plate as a single subsystem. Comparisons between FEM and SEA showed that this approach was appropriate when using transmission coefficients calculated with a combination of Bloch and wave theory when the ribs are parallel to the junction line and when using transmission coefficients calculated assuming angle-dependent bending stiffness when the ribs are perpendicular to the junction line.

Above the frequency band in which the bays of the ribbed receiving plate support local bending modes and when the ribs are parallel to the junction line, there was a significant reduction in the vibration level across successive bays that are increasingly distant from the junction. This occurred due to spatial filtering. The agreement between FEM and ASEA indicated that ASEA was able to correctly incorporate the indirect coupling associated with this transmission mechanism. Comparisons between FEM and SEA also showed reasonable agreement when treating the ribbed plate as a single subsystem to determine a spatial average vibration over all the bays of the ribbed plate. However, it was noted that this could be problematic. For the purpose of engineering noise control it is concluded that it is not appropriate to 


\begin{tabular}{|c|c|c|c|c|c|c|c|c|c|c|}
\hline $\operatorname{TOB}(\mathrm{Hz})=100$ & 160 & 250 & 400 & 630 & $1 \mathrm{k}$ & $1.6 \mathrm{k}$ & $2.5 \mathrm{k}$ & $4 \mathrm{k}$ & $6.3 \mathrm{k}$ & $10 \mathrm{k}$ \\
\hline$N_{\text {Plate3 }}=2.4$ & 3.8 & 6.0 & 9.6 & 15.1 & 24.0 & 38.4 & 60.0 & 95.9 & 151.1 & 239.9 \\
\hline$N_{\text {Plate2 }}=1.6$ & 2.6 & 4.0 & 6.4 & 10.1 & 16.0 & 25.6 & 40.0 & 64.0 & 100.7 & 159.9 \\
\hline$N_{\text {Bay-Plate1 }}=$ & & & 1 & 1 & 2 & 4 & 3 & 12 & 15 & 17 \\
\hline
\end{tabular}

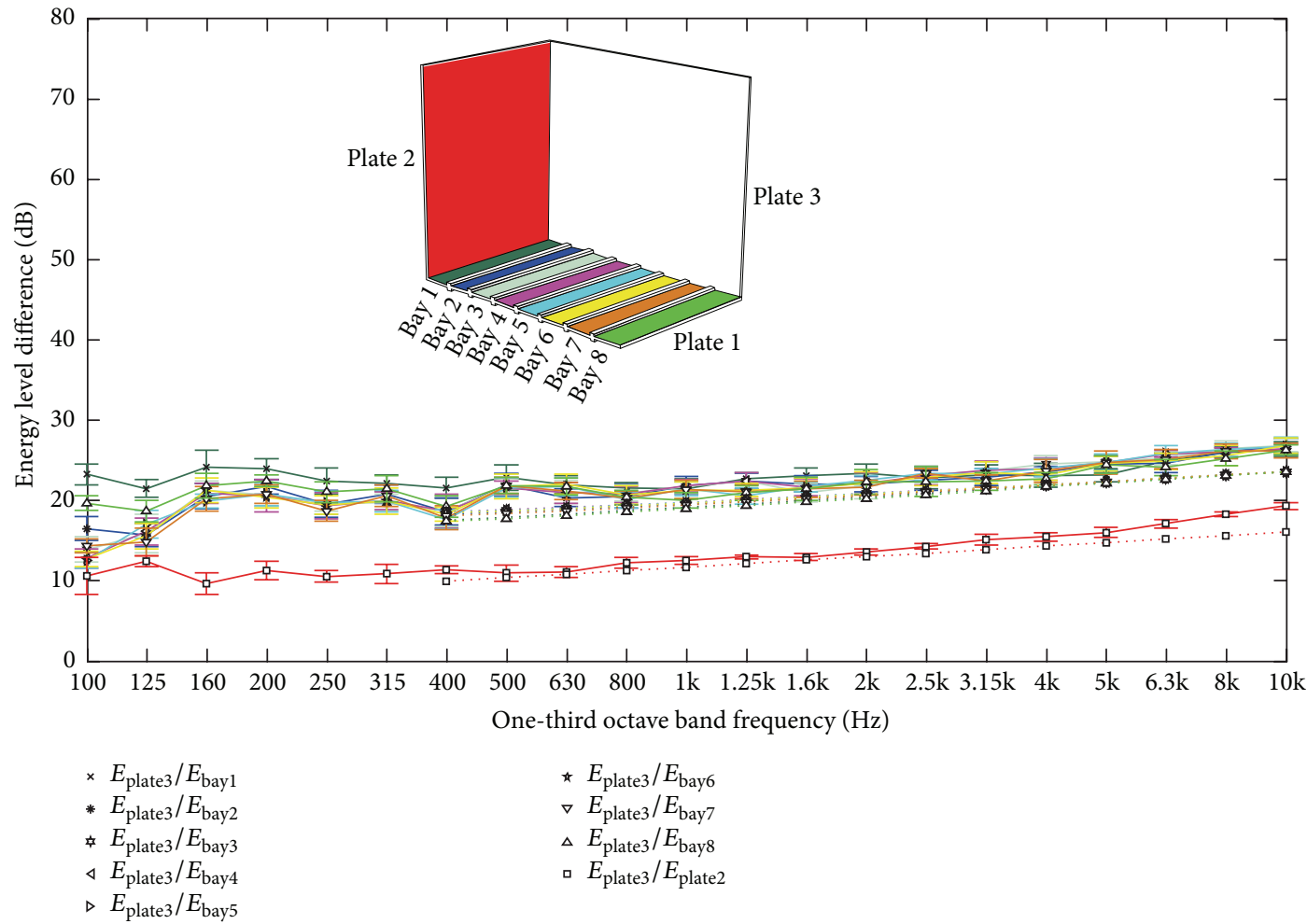

Figure 14: Three coupled plates. Excitation: Plate 3. Energy level differences between the isotropic plate (Plate 3) and each of the bays that form the other periodic ribbed plate (Plate 1) as well as the other isotropic plate (Plate 2). Comparison between FEM and ASEA (FEM data are shown using markers with continuous lines; ASEA data are shown using markers with dotted lines).

use SEA in the high-frequency range for the ribbed plates considered in this paper because the vibration level in the first and last bays differed by up to $56 \mathrm{~dB}$. Therefore any prediction of sound radiation from the ribbed plate or assessment of the vibration exposure of sensitive machinery mounted in individual bays would be incorrect or misleading. However, when the ribs are perpendicular to the junction line it was shown that the response can be predicted either by using SEA where the periodic ribbed plate is modelled as a single subsystem with angle-dependent bending stiffness or by using ASEA.

For the crossover from SEA to ASEA it is proposed that, in the frequency band which contains the fundamental bending mode of each bay, the predicted values from SEA and ASEA can be averaged to provide a smooth changeover between the two models.

The findings from the L-junctions were assessed with a more realistic system of three coupled plates which introduced flanking transmission. This provided further confirmation that a wide frequency range can be covered by using both SEA and ASEA for systems of coupled plates where some or all of the plates are periodic ribbed plates. However, for the many engineering constructions that are formed from ribbed plates, it is not possible to say a priori whether it is sufficient to use only SEA, and therefore ASEA models should always be considered at frequencies above the fundamental bending mode of the bays on the ribbed plate.

\section{Conflict of Interests}

The authors declare that there is no conflict of interests regarding the publication of this paper.

\section{Acknowledgments}

Dr. Jianfei Yin is grateful for the support provided by the National Natural Science Foundation of China (Grant no. 51405502), China Scholarship Council, the Acoustics Research Unit (ARU) at the University of Liverpool and the National University of Defense Technology. Both authors are grateful to Dr. Gary Seiffert for his assistance and advice with the experimental work in the ARU laboratories. 


\begin{tabular}{rlrlccccccrr} 
TOB $(\mathrm{Hz})$ & $=100$ & 160 & 250 & 400 & 630 & $1 \mathrm{k}$ & $1.6 \mathrm{k}$ & $2.5 \mathrm{k}$ & $4 \mathrm{k}$ & $6.3 \mathrm{k}$ & $10 \mathrm{k}$ \\
$N_{\text {Plate3 }}$ & $=2.4$ & 3.8 & 6.0 & 9.6 & 15.1 & 24.0 & 38.4 & 60.0 & 95.9 & 151.1 & 239.9 \\
$N_{\text {Plate2 }}$ & $=1.6$ & 2.6 & 4.0 & 6.4 & 10.1 & 16.0 & 25.6 & 40.0 & 64.0 & 100.7 & 159.9 \\
$N_{\text {Bay-Plate1 }}$ & $=$ & & & 1 & 1 & 2 & 4 & 3 & 12 & 15 \\
\hline
\end{tabular}

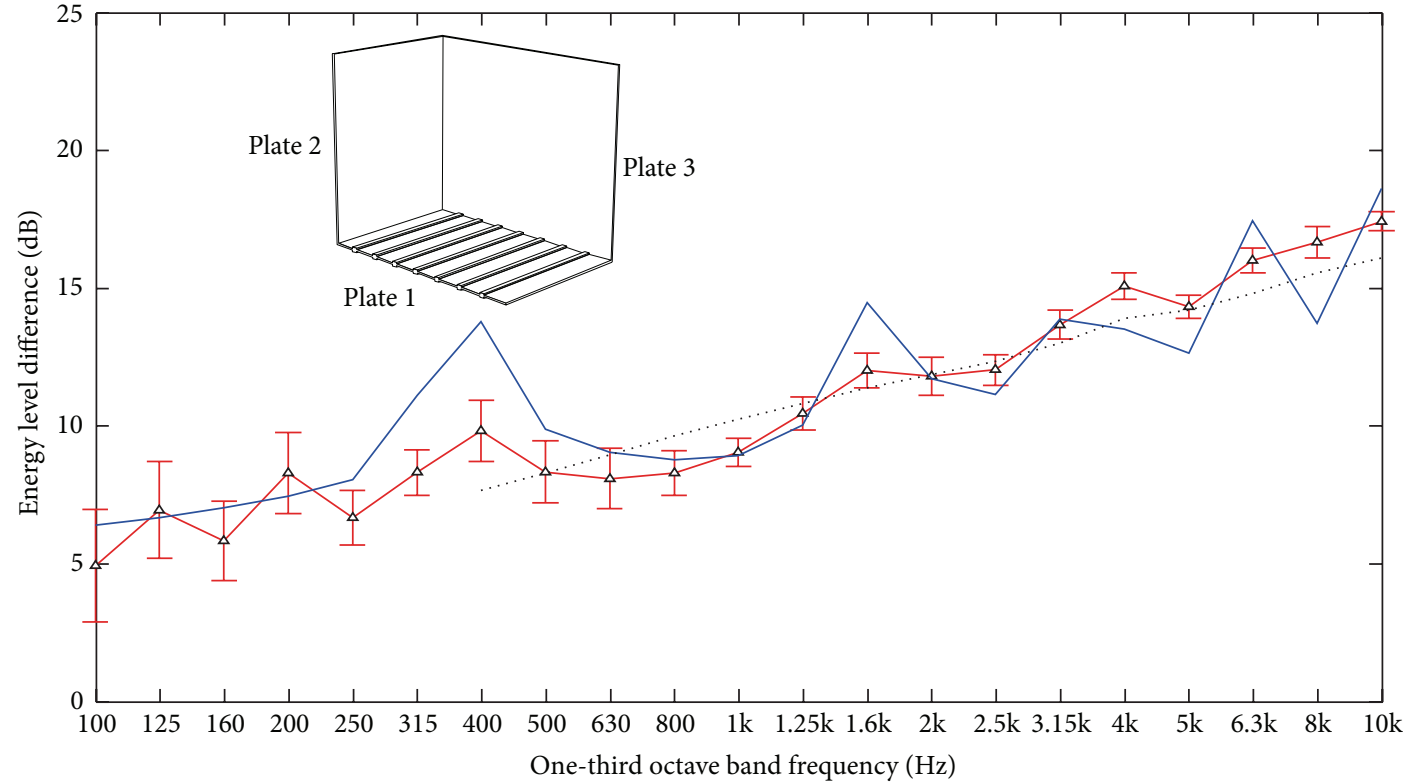

$\begin{array}{ll}\triangle & E_{1} / E_{2}: \text { FEM } \\ - & E_{1} / E_{2}: \text { SEA } \\ \cdots \cdots & E_{1} / E_{2}: \text { ASEA }\end{array}$

(a)

\begin{tabular}{|c|c|c|c|c|c|c|c|c|c|c|}
\hline $\operatorname{TOB}(\mathrm{Hz})=100$ & 160 & 250 & 400 & 630 & $1 \mathrm{k}$ & $1.6 \mathrm{k}$ & $2.5 \mathrm{k}$ & $4 \mathrm{k}$ & $6.3 \mathrm{k}$ & $10 \mathrm{k}$ \\
\hline$N_{\text {Plate3 }}=2.4$ & 3.8 & 6.0 & 9.6 & 15.1 & 24.0 & 38.4 & 60.0 & 95.9 & 151.1 & 239.9 \\
\hline$N_{\text {Plate2 }}=1.6$ & 2.6 & 4.0 & 6.4 & 10.1 & 16.0 & 25.6 & 40.0 & 64.0 & 100.7 & 159.9 \\
\hline Bay-Plate1 = & & & 1 & 1 & 2 & 4 & 3 & 12 & 15 & 17 \\
\hline
\end{tabular}

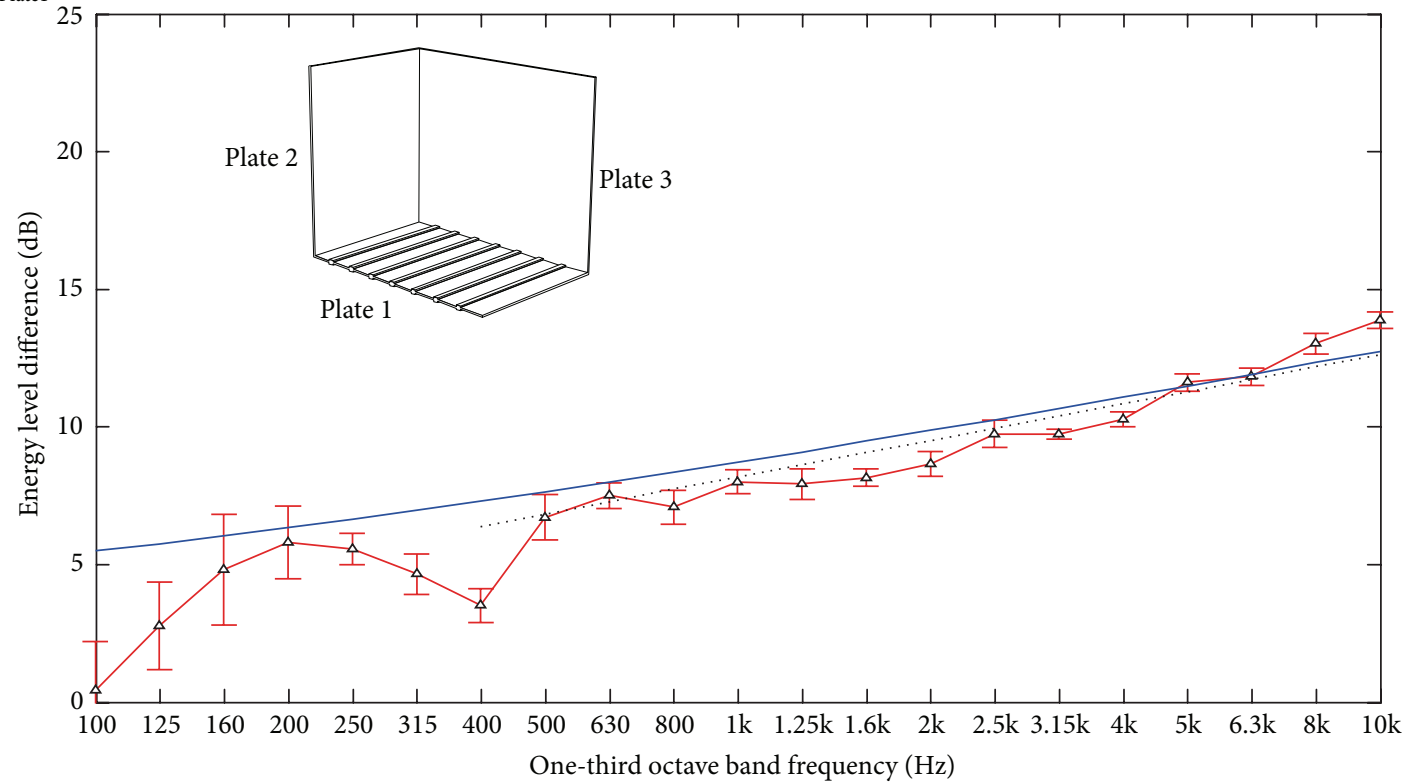

$\begin{array}{ll}\neg & E_{1} / E_{3}: \text { FEM } \\ - & E_{1} / E_{3}: \text { SEA } \\ \cdots \cdots E_{1} / E_{3}: \text { ASEA }\end{array}$

(b)

FIGURE 15: Three coupled plates. Excitation: Plate 1. Energy level differences between (a) the periodic ribbed plate (Plate 1) and the isotropic, homogeneous plate (Plate 2) and (b) the periodic ribbed plate (Plate 1) and the isotropic, homogeneous plate (Plate 3 ). 

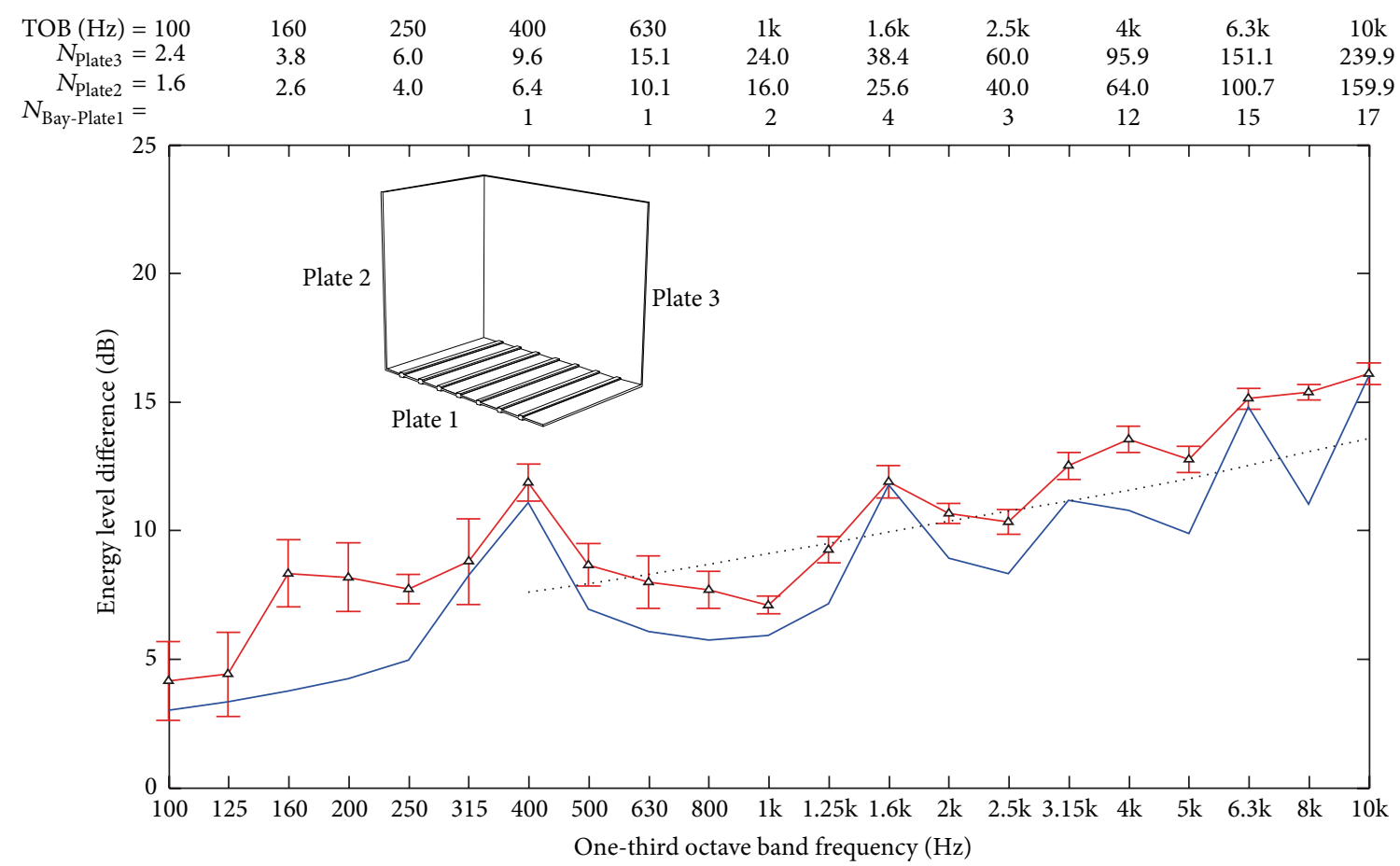

$\triangle E_{2} / E_{1}:$ FEM

$-E_{2} / E_{1}:$ SEA

$\cdots E_{2} / E_{1}$ : ASEA

(a)

\begin{tabular}{rlcccccccrrr} 
TOB $(\mathrm{Hz})$ & $=100$ & 160 & 250 & 400 & 630 & $1 \mathrm{k}$ & $1.6 \mathrm{k}$ & $2.5 \mathrm{k}$ & $4 \mathrm{k}$ & $6.3 \mathrm{k}$ & $10 \mathrm{k}$ \\
$N_{\text {Plate3 }}$ & $=2.4$ & 3.8 & 6.0 & 9.6 & 15.1 & 24.0 & 38.4 & 60.0 & 95.9 & 151.1 & 239.9 \\
$N_{\text {Plate2 }}$ & $=1.6$ & 2.6 & 4.0 & 6.4 & 10.1 & 16.0 & 25.6 & 40.0 & 64.0 & 100.7 & 159.9 \\
$N_{\text {Bay-Plate1 }}$ & $=$ & & & 1 & 1 & 2 & 4 & 3 & 12 & 15 \\
\hline
\end{tabular}

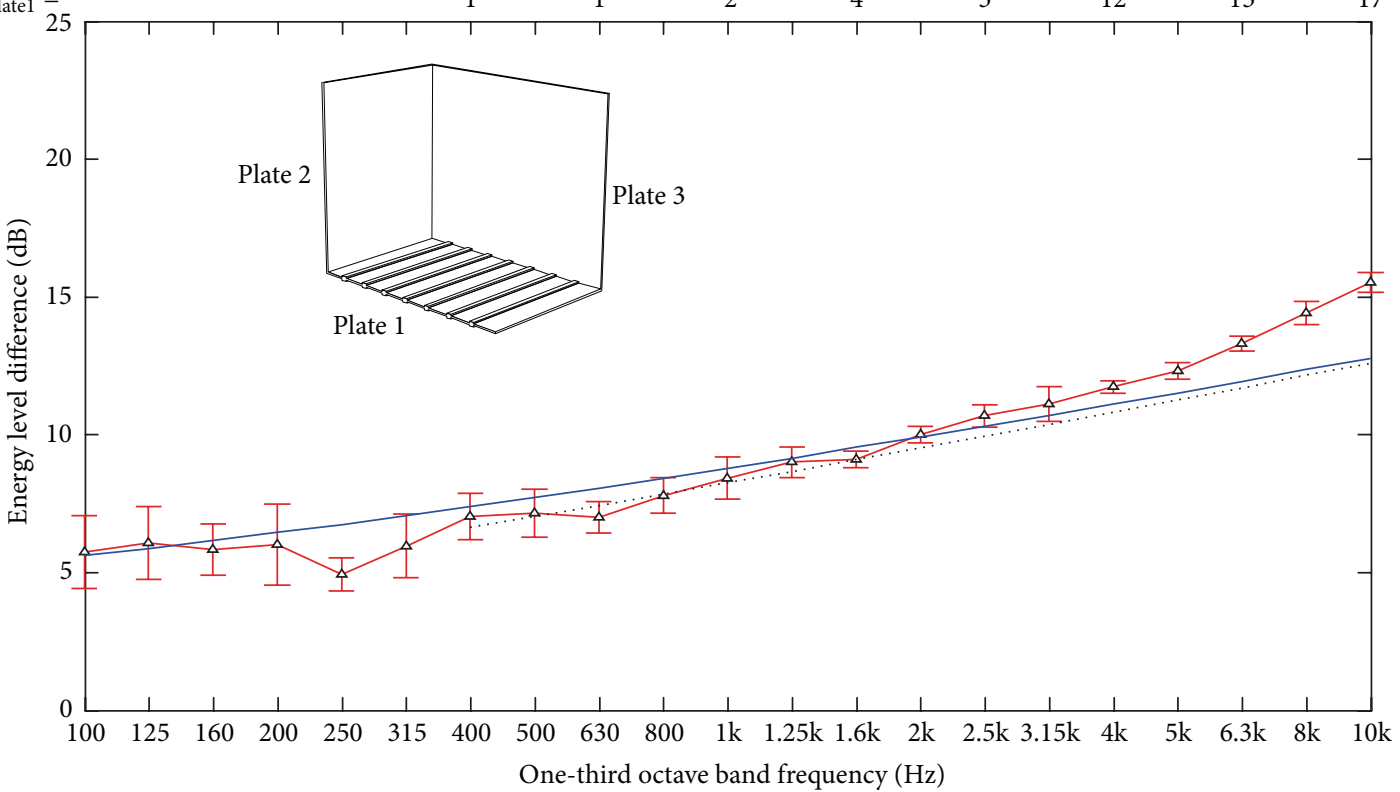

$\begin{array}{ll}\triangle & E_{2} / E_{3}: \text { FEM } \\ - & E_{2} / E_{3}: \text { SEA } \\ \cdots \cdots & E_{2} / E_{3}: \text { ASEA }\end{array}$

(b)

Figure 16: Three coupled plates. Excitation: Plate 2. Energy level differences between (a) the isotropic, homogeneous plate (Plate 2) and the periodic ribbed plate (Plate 1) and (b) the isotropic, homogeneous plate (Plate 2) and the isotropic, homogeneous plate (Plate 3). 


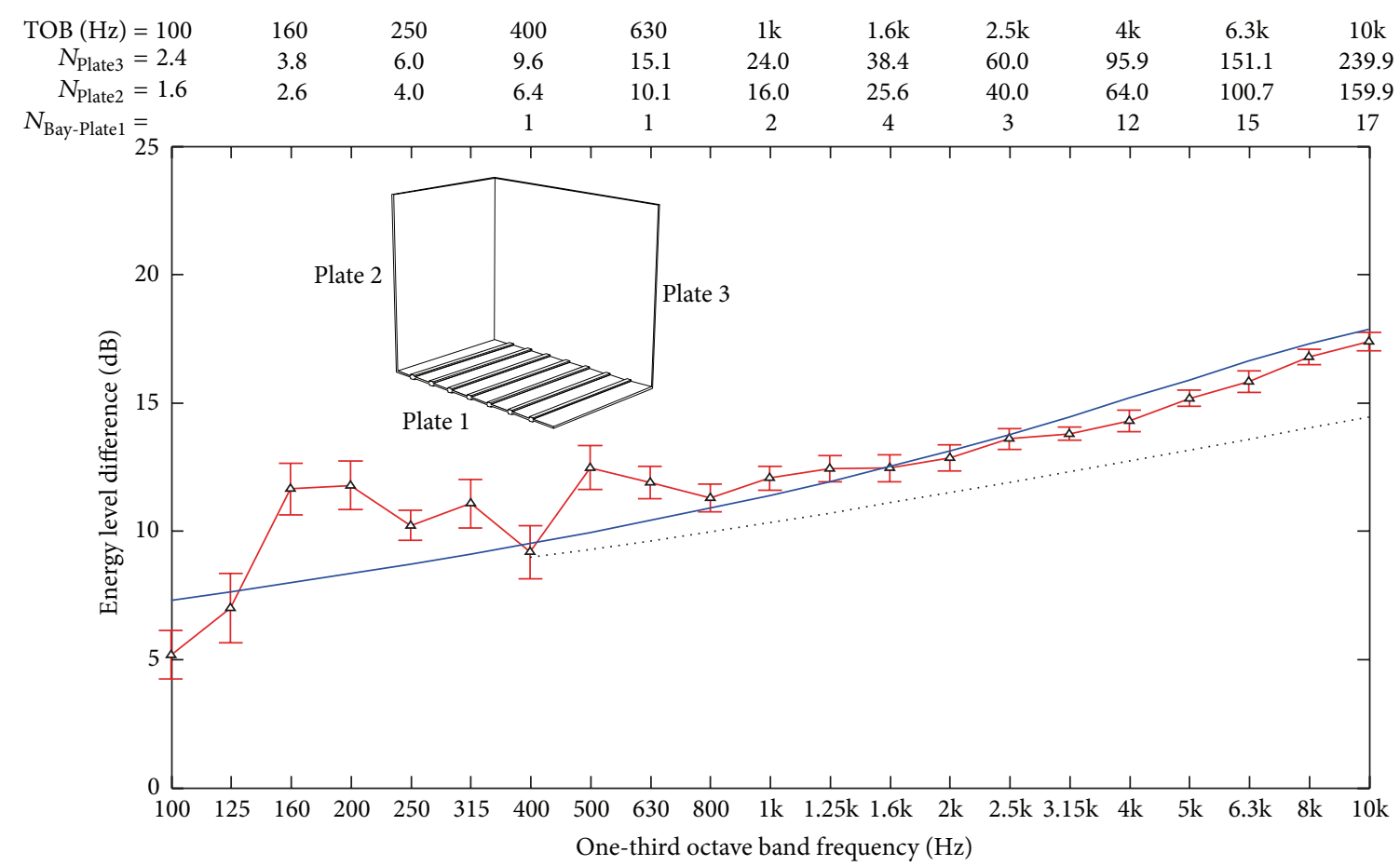

$\triangle E_{3} / E_{1}:$ FEM

$-E_{3} / E_{1}:$ SEA

$\cdots \cdot E_{3} / E_{1}$ : ASEA

(a)
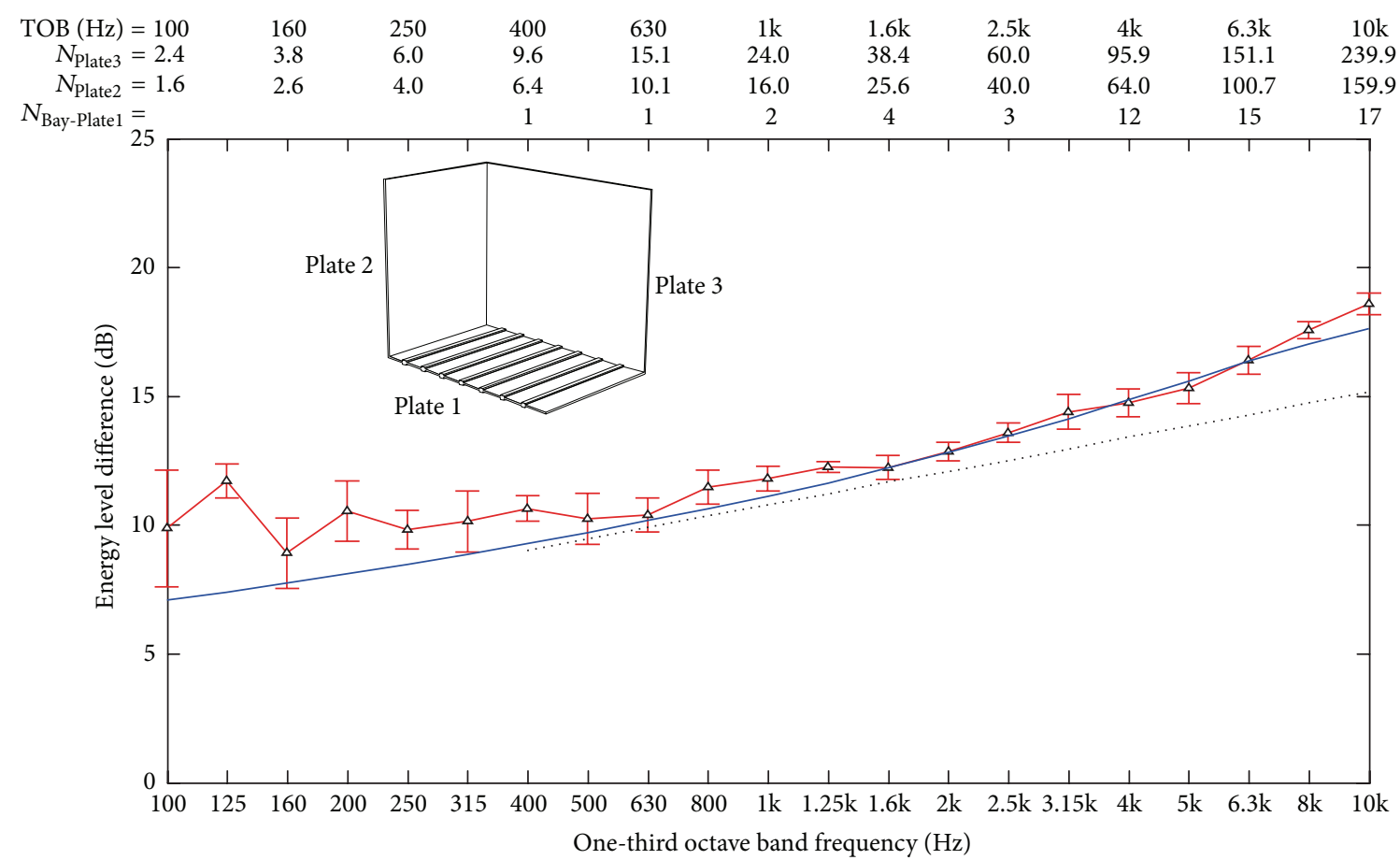

$E_{3} / E_{2}: \mathrm{FEM}$

$E_{3} / E_{2}$ : SEA

$E_{3} / E_{2}$ : ASEA

(b)

Figure 17: Three coupled plates. Excitation: Plate 3. Energy level differences between (a) the isotropic, homogeneous plate (Plate 3) and the periodic ribbed plate (Plate 1) and (b) the isotropic, homogeneous plate (Plate 3) and the isotropic, homogeneous plate (Plate 2). 


\section{References}

[1] S. Troitsky, Stiffened Plates: Bending, Stability, and Vibrations, Elsevier Scientific, 1976.

[2] M. Heckl, "Wave propagation on beam-plate systems," Journal of the Acoustical Society of America, vol. 33, no. 5, pp. 640-651, 1961.

[3] D. J. Mead, "Vibration response and wave propagation in periodic structures," Journal of Engineering for Industry, vol. 93, no. 3, pp. 783-792, 1971.

[4] S. S. Mester and H. Benaroya, "Periodic and near-periodic structures," Shock and Vibration, vol. 2, no. 1, pp. 69-95, 1995.

[5] R. H. Lyon and R. G. DeJong, Theory and Application of Statistical Energy Analysis, Butterworth-Heinemann, Newton, Mass, USA, 1995.

[6] M. Robinson and C. Hopkins, "Prediction of maximum timeweighted sound and vibration levels using transient statistical energy analysis. Part 1: theory and numerical implementation," Acta Acustica united with Acustica, vol. 100, no. 1, pp. 46-56, 2014.

[7] M. Robinson and C. Hopkins, "Prediction of maximum timeweighted sound and vibration levels using transient statistical energy analysis. Part 2: experimental validation," Acta Acustica united with Acustica, vol. 100, no. 1, pp. 57-66, 2014.

[8] F. J. Fahy, "Statistical energy analysis: a critical overview," Philosophical Transactions of the Royal Society of London A, vol. 346, pp. 431-447, 1994.

[9] K. H. Heron, "Advanced statistical energy analysis," Philosophical Transactions of the Royal Society A: Mathematical, Physical and Engineering Sciences, vol. 346, no. 1681, pp. 501-510, 1994.

[10] J. Yin and C. Hopkins, "Prediction of high-frequency vibration transmission across coupled, periodic ribbed plates by incorporating tunneling mechanisms," Journal of the Acoustical Society of America, vol. 133, no. 4, pp. 2069-2081, 2013.

[11] D. Wilson and C. Hopkins, "Analysis of bending wave transmission using beam tracing with advanced statistical energy analysis for periodic box-like structures affected by spatial filtering," Journal of Sound and Vibration, vol. 341, pp. 138-161, 2015.

[12] J. Yin and C. Hopkins, "Treating periodic ribbed plates with symmetric ribs as individual subsystems in Statistical Energy Analysis: models for bending wave transmission across Ljunctions in the low- and mid-frequency ranges," Journal of Sound and Vibration, vol. 344, pp. 221-241, 2015.

[13] R. S. Langley and A. N. Bercin, "Wave intensity analysis of high frequency vibrations," Philosophical Transactions of the Royal Society A, vol. 346, no. 1681, pp. 489-499, 1994.

[14] Y. K. Tso and C. H. Hansen, "The transmission of vibration through a coupled periodic structure," Journal of Sound and Vibration, vol. 215, no. 1, pp. 63-79, 1998.

[15] I. Bosmans, P. Mees, and G. Vermeir, "Structure-borne sound transmission between thin orthotropic plates: Analytical solutions," Journal of Sound and Vibration, vol. 191, no. 1, pp. 75-90, 1996.

[16] C. H. Hodges and J. Woodhouse, "Theories of noise and vibration transmission in complex structures," Reports on Progress in Physics, vol. 49, no. 2, pp. 107-170, 1986.

[17] C. H. Hodges and J. Woodhouse, "Vibration isolation from irregularity in a nearly periodic structure: theory and measurements," Journal of the Acoustical Society of America, vol. 74, no. 3, pp. 894-905, 1983. 

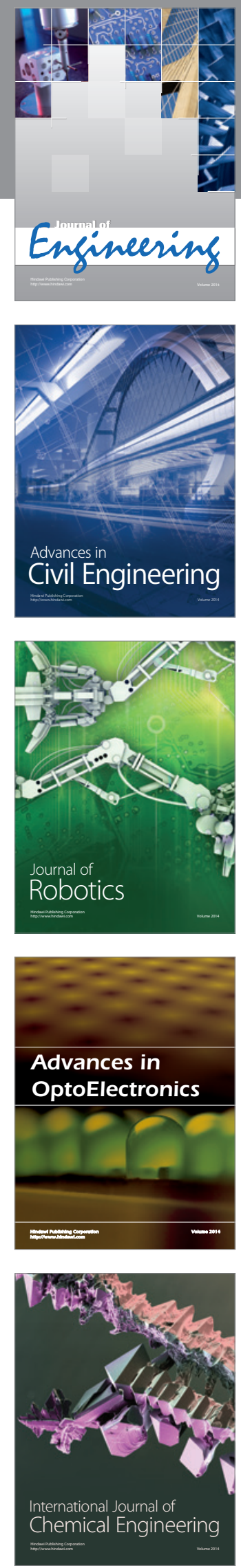

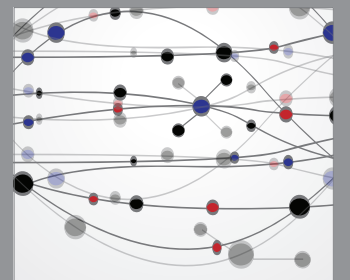

The Scientific World Journal
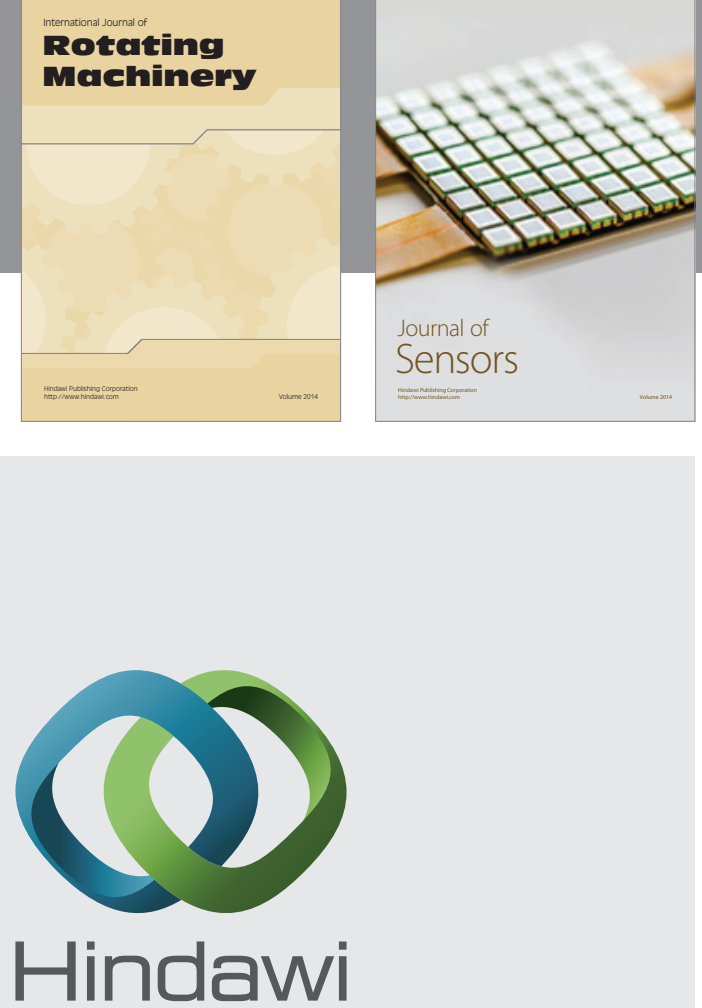

Submit your manuscripts at http://www.hindawi.com
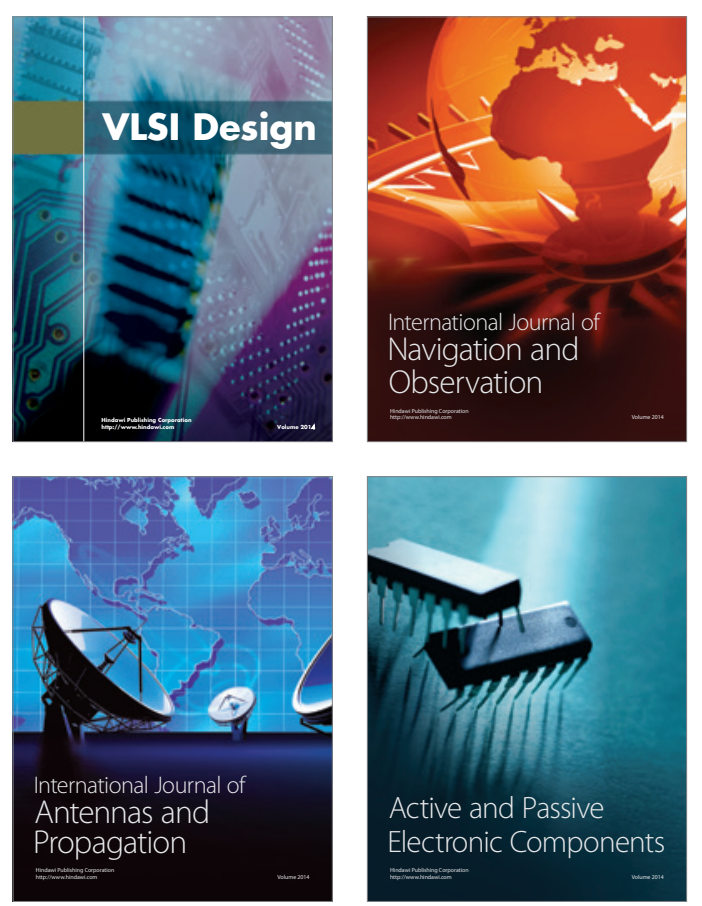
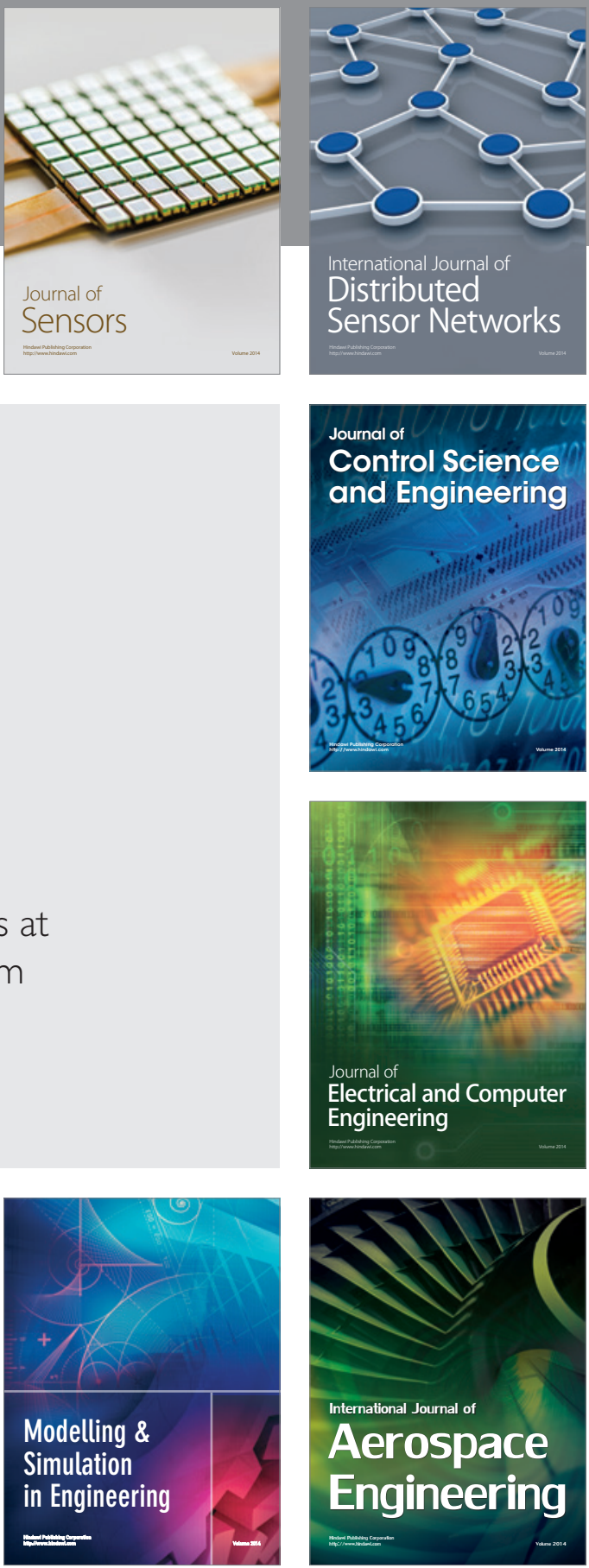

Journal of

Control Science

and Engineering
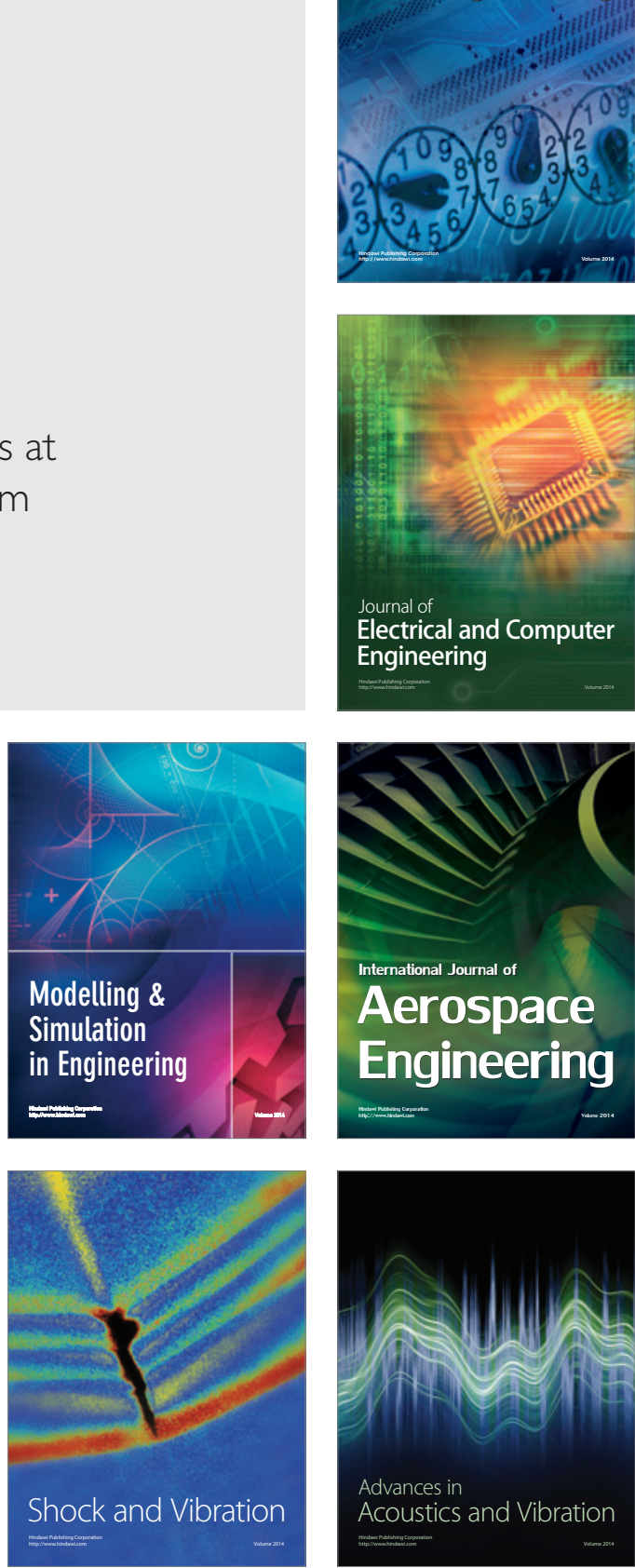